Article

\title{
Spectroscopic Ellipsometry Studies of $n-i-p$ Hydrogenated Amorphous Silicon Based Photovoltaic Devices
}

\author{
Laxmi Karki Gautam, Maxwell M. Junda, Hamna F. Haneef, Robert W. Collins \\ and Nikolas J. Podraza *
}

Wright Center for Photovoltaics Innovation \& Commercialization and Department of Physics \& Astronomy, University of Toledo, Toledo, OH 43606, USA; Laxmi.KarkiGautam@rockets.utoledo.edu (L.K.G.);

Maxwell.Junda@rockets.utoledo.edu (M.M.J.); Hamna.Haneef@rockets.utoledo.edu (H.F.H.);

Robert.Collins@utoledo.edu (R.W.C.)

* Correspondence: Nikolas.Podraza@utoledo.edu; Tel.: +1-419-530-3708

Academic Editor: Joshua M. Pearce

Received: 1 January 2016; Accepted: 18 February 2016; Published: 25 February 2016

\begin{abstract}
Optimization of thin film photovoltaics (PV) relies on characterizing the optoelectronic and structural properties of each layer and correlating these properties with device performance. Growth evolution diagrams have been used to guide production of materials with good optoelectronic properties in the full hydrogenated amorphous silicon (a-Si:H) PV device configuration. The nucleation and evolution of crystallites forming from the amorphous phase were studied using in situ near-infrared to ultraviolet spectroscopic ellipsometry during growth of films prepared as a function of hydrogen to reactive gas flow ratio $R=\left[\mathrm{H}_{2}\right] /\left[\mathrm{SiH}_{4}\right]$. In conjunction with higher photon energy measurements, the presence and relative absorption strength of silicon-hydrogen infrared modes were measured by infrared extended ellipsometry measurements to gain insight into chemical bonding. Structural and optical models have been developed for the back reflector (BR) structure consisting of sputtered undoped zinc oxide $(\mathrm{ZnO})$ on top of silver (Ag) coated glass substrates. Characterization of the free-carrier absorption properties in $\mathrm{Ag}$ and the $\mathrm{ZnO}+\mathrm{Ag}$ interface as well as phonon modes in $\mathrm{ZnO}$ were also studied by spectroscopic ellipsometry. Measurements ranging from 0.04 to $5 \mathrm{eV}$ were used to extract layer thicknesses, composition, and optical response in the form of complex dielectric function spectra $\left(\varepsilon=\varepsilon_{1}+\mathrm{i} \varepsilon_{2}\right)$ for $\mathrm{Ag}, \mathrm{ZnO}$, the $\mathrm{ZnO}+\mathrm{Ag}$ interface, and undoped a-Si:H layer in a substrate $n-i-p$ a-Si:H based PV device structure.
\end{abstract}

Keywords: spectroscopic ellipsometry; hydrogenated silicon; infrared spectra; photovoltaic devices

\section{Introduction}

Development of thin film technologies based on amorphous silicon and germanium, including photovoltaic (PV) devices, involves understanding of material electrical and optical properties [1-4]. It is essential to measure, monitor, and control the thickness, structure, phase, and composition of solar cell component layers in the same configuration used in manufacturing, especially for devices processed over large areas. Doped ( $n$-type and $p$-type) and undoped (intrinsic) hydrogenated silicon (Si:H) thin films are used in single, tandem, and multijunction solar cell applications in both $n-i-p$ substrate and $p-i-n$ superstrate configurations [5-10]. These Si:H films prepared by plasma enhanced chemical vapor deposition (PECVD) may exhibit several structural transitions during growth in the PV device configuration. The structural evolution of Si:H can be controlled by dilution of a reactive silicon carrying gases like silane $\left(\mathrm{SiH}_{4}\right)$ with hydrogen $\left(\mathrm{H}_{2}\right)$ during deposition. The microstructural 
evolution of Si:H has been studied for layers deposited on different bulk and thin film substrates with varying degrees of surface roughness, including native and thermal oxide coated crystalline silicon, glass, polyethylene naphthalate (PEN) polymer, as well as underlying structurally distinct Si:H layers prepared under different deposition conditions. A primary technique for studying this growth evolution is the use of near infrared (IR) to ultraviolet (UV) in situ, real time spectroscopic ellipsometry (RTSE) applied during Si:H thin film growth [2,4,7,11,12]. RTSE involves collection of ellipsometric spectra as a function of time during a process such as thin film deposition, typically using a multichannel instrument which collects all photon energies in parallel with serial readout of pixels arranged in a one dimensional (1-D) detector. The data acquisition time is typically chosen such that highest signal-to-noise is obtained via averaging of multiple optical cycles over a period of time in which typically only 0.1 to $10 \AA$ of material accumulates. Koh et al. [7] reported the growth evolution of intrinsic $\mathrm{Si}: \mathrm{H}$ on native oxide covered crystalline silicon, amorphous $\mathrm{Si}: \mathrm{H}$ (a-Si:H) films prepared without additional hydrogen dilution, and on newly deposited $\sim 200 \AA$ p-type microcrystalline or nanocrystalline Si:H (nc-Si:H). These results demonstrate that the nature of the underlying material influences nucleation of crystallites, suppressing nucleation with underlying a-Si:H and promoting nucleation with underlying nc-Si:H. The growth evolution of $p$-layers on specular zinc oxide $(\mathrm{ZnO})$ coated glass and the ability to promote a high nucleation density of nc-Si:H were studied by Rovira et al. [11]. In another study of the growth evolution of $p$-type Si:H on ZnO coated glass and $\mathrm{ZnO}$ over-coating tin oxide $\left(\mathrm{SnO}_{2}\right)$, Koval et al. [12] reported that valid material properties and device performance correlations can be better realized for any given material when the properties are obtained from deposition on similar substrates with similar thicknesses as those used in the respective device. The generation of so-called "deposition phase diagrams" or "growth evolution diagrams" for vhf and rf PECVD of Si:H films determined that vhf PECVD shows significant differences in structural evolution with processing conditions, namely the plasma excitation frequency [13]. Growth evolution diagrams have been developed by Stoke et al. for intrinsic a-Si:H, amorphous silicon germanium alloys, and nc-Si:H for top, middle, and bottom cell $i$-layers used in triple junction devices [14]. Dahal et al. reported growth evolution diagrams for intrinsic and $p$-type Si:H deposited on unoptimized $n$-layer $/ \mathrm{ZnO} / \mathrm{Ag}$ back reflector (BR) coated PEN in $n-i-p$ configuration PV devices [15]. Overall these results and analysis procedures developed here are applicable to more directly relating properties of layers in the device configuration, as obtained by non-destructive measurements, with variations in device performance. These types of measurements have been demonstrated for a-Si:H solar cells deposited on planar substrates as described here and also on those incorporating macroscopic roughness or texturing [16-18].

Both a-Si:H and nc-Si:H component materials are used in state-of-the-art Si:H based PV devices. nc-Si:H, either as individual layers or in PV junctions, has significant enhancement in near IR absorption of the solar spectrum and high stability under prolonged illumination in contrast to its amorphous counterpart $[19,20]$. The quantitative analysis, characterization, and control of the relative nanocrystalline and amorphous volume fractions within mixed-phase films is also a major challenge in $\mathrm{Si}: \mathrm{H}$ manufacturing. Most often the nanocrystalline fraction is estimated from $x$-ray diffraction or Raman spectroscopy, which can yield values ranging an order of magnitude [6,21,22]. Although these measurements are valuable, limitations exist. Typically ex situ $x$-ray diffraction measurements average information over the full depth of a thin film sample, and ex situ Raman spectroscopy averages information over a finite penetration depth into the sample that is dependent upon the wavelength of the probing laser, its power, and the absorption coefficient of the material. Profiling these materials non-invasively is an even greater challenge due to probe penetration depth limitations and likely non-uniform crystallite fraction with depth into films. Si:H films may be inhomogeneous with thickness as crystallites nucleate from and coexist with the amorphous phase. Deconvolving gradients in crystallinity from ex situ $x$-ray diffraction and Raman spectroscopy measurements requires multiple samples, while in situ RTSE measurements applied during film deposition have been used to quantify structural gradients in crystallinity within a single film. 
A wealth of information can be extracted from these types of RTSE measurements applied at a single spot on a sample surface, but additional property variations related to sample non-uniformity have also been obtained by ex situ mapping spectroscopic ellipsometry (SE) [23-26]. In mapping SE, the sample and multichannel ellipsometer, similar to the instrument used in RTSE studies, are mechanically translated with respect to the each other in one or more dimensions to obtain ellipsometric spectra as a function of spatial position. In the case of $\mathrm{Si}: \mathrm{H}$, simplified structural models based on results from RTSE measurements are applied to probe subtle variations in material opto-electronic response such as the band gap of a-Si:H, film thickness, surface roughness thickness, and nanocrystallite fraction in mixed phase materials. These types of measurements have been applied to Si:H [23,24], cadmium telluride [26], and copper indium gallium diselenide [25] PV devices ranging from tens of square centimeters on the laboratory scale to full industrially prepared panels. Thus, improvements in understanding and quantifying the structural transition of $\mathrm{Si}: \mathrm{H}$ from amorphous to nanocrystalline, as obtained from single spot in situ RTSE measurements, can be applied to develop more advanced optical models and more thoroughly analyze mapping SE measurements collected over larger areas.

We have applied SE from 0.734 to $5.88 \mathrm{eV}$ to extract layer thicknesses, interface composition, and optical response in the form of complex dielectric function spectra $\left(\varepsilon=\varepsilon_{1}+\mathrm{i} \varepsilon_{2}\right)$ for all $\mathrm{Ag}$, $\mathrm{ZnO}$, and doped and undoped PECVD Si:H layers found in substrate $n-i-p$ PV devices. These studies begin with characterization of $\mathrm{ZnO} / \mathrm{Ag}$ BRs and have been applied over the near IR to UV spectral range [27,28]. The purpose of BR structures is to increase the optical path length of light within the absorber layer of the PV device, where each photon absorbed has the potential to generate electron-hole pairs and thus electrical current. Any light not absorbed in the first pass of light through the absorber layer is reflected or scattered by the BR back into the absorber layer. Thus PV absorber layers can be made thinner or from materials with low minority carrier diffusion lengths. Due to the substrate dependence of $\mathrm{Si}: \mathrm{H}$ growth, the same $\mathrm{ZnO} / \mathrm{Ag} \mathrm{BR}$ structures were used to study the growth evolution of doped and undoped Si:H required for use in $n$-i-p a-Si:H PV devices. RTSE using a global $\Sigma \sigma$-minimization analysis procedure has been used to track the behavior of structural transitions in $\mathrm{Si}: \mathrm{H}$ deposited in the $n-i-p$ PV device structure, as functions of hydrogen to reactive gas flow ratio $R=\left[\mathrm{H}_{2}\right] /\left[\mathrm{SiH}_{4}\right]$, to produce growth evolution diagrams for undoped, $p$-type, and $n$-type layers. Global $\Sigma \sigma$-minimization analysis of RTSE involves using test structural parameters, most commonly a bulk layer thickness $\left(d_{b}\right)$ and surface roughness thickness $\left(d_{s}\right)$, to numerically solve for test $\varepsilon$ [29]. These test values of $\varepsilon$ are then used to fit other ellipsometric spectra collected at different times when the film is relatively homogeneous. The approach is iterated in order to obtain numerically inverted $\varepsilon$ yielding the lowest spectrally and time-averaged error, $\sigma$, over the multiple time measurements selected. The numerically inverted $\varepsilon$ that minimizes $\sigma$ are then used to determine structural parameter variations over the full set of RTSE data, with material transitions identified either in the structural parameters themselves or by increases in the error function. Virtual interface analysis (VIA) [30,31] has similarly been applied to track the depth profile of nc-Si:H as well as the formation and stabilization of voids throughout intrinsic layer nc-Si:H growth. In VIA, the full sample stack is not analyzed. Instead, optical properties of a pseudo-substrate are generated from ellipsometric spectra collected earlier in the deposition by numerically inverting the measurement to obtain $\varepsilon$ using a simplified model consisting of a semi-infinite pseudo-substrate and a surface roughness layer. The effective $\varepsilon$ for the pseudo-substrate contains information of all underlying material(s) in the sample stack and is then used as the semi-infinite substrate for analysis of subsequent data sets. In this sense, the time derivative of ellipsometric spectra is analyzed and full understanding of the underlying structure is not required in the analysis procedure. When combined with $\Sigma \sigma$-minimization approaches for structurally graded $\mathrm{Si}: \mathrm{H}, \mathrm{VIA}$ yields $\varepsilon$ for both the nc-Si:H and a-Si:H components as well as the time and bulk layer thickness dependence of component material fractions in the overlayer of material accumulated between each pseudo-substrate and subsequent data set pair. These techniques are used to provide guidance for the deposition and in situ characterization of a-Si:H, nc-Si:H, and mixed-phase (a+nc)-Si:H layers during growth in device structures. 
In addition to RTSE studies of material growth evolution limited to the near IR to UV spectral range, we also have used ex situ, room temperature IR-extended SE (IR-SE) from 0.04 to $0.75 \mathrm{eV}$ using a Fourier transform IR ellipsometer operating over this spectral range. This extension enables spectra in $\varepsilon$ for $\mathrm{Si}: \mathrm{H}$ and BR components layers to be determined from the mid-IR to UV wavelength range. Simultaneous analysis of ellipsometric spectra collected from multiple samples consisting of BR and $i$-layer/ $n$-layer/BR stacks deposited on borosilicate glass substrates was used to yield a common $\varepsilon$ for each layer while structural parameters such as $d_{b}$ and $d_{s}$ may be varied separately as in RTSE data analysis $[4,7,11,13-15,27,28]$ and similar in methodology to the divided spectral range approach [32]. A common parameterization of $\varepsilon$ is used to fit ex situ ellipsometric spectra collected from separate near IR-UV multichannel and FTIR ellipsometers. This approach yields a continuous set of spectra in $\varepsilon$ for each material, although the particular beam spot location on the sample surface may not be the same during measurement using each ellipsometer [33]. The results of the analysis of IR-SE data were used to study absorption in the BR components, which can be used to extract electrical transport properties and phonon modes. In addition, $\varepsilon$ for protocrystalline intrinsic a-Si:H extracted from IR-SE data is sensitive to the silicon-hydrogen bonding configuration. Comparison of optical absorption features affords a method of assessing film structural and chemical character, which then suggests ways to improve material quality and potentially device performance $[34,35]$. PV devices incorporating optimization principles based on IR spectroscopy and RTSE analyzed for each layer in the device configuration have exhibited relatively high performance [23,34].

In situ RTSE studies have been used to yield growth evolution phase diagrams of each doped and undoped Si:H layer in the $n$-i- $p$ PV device configuration and structural evolution profiles of crystallite and void fractions. The information from growth evolution diagrams was used to design PV device structures, lacking the $p$-layer and incorporating only the amorphous phase, for characterization using $e x$ situ IR-extended SE. Results of $e x$ situ IR-extended SE combined with $e x$ situ near IR-UV SE have been used to obtain spectra in $\varepsilon$ from 0.04 to $5.0 \mathrm{eV}$ for $\mathrm{ZnO}$ and a-Si:H in the $\mathrm{BR} / n-i-p$ a-Si:H solar cell configuration. Higher energy transitions related to electronic structure in $\mathrm{Ag}, \mathrm{ZnO}$, and a-Si:H; the band gap in $\mathrm{ZnO}$ and a-Si:H; a plasmon feature in the $\mathrm{Ag}+\mathrm{ZnO}$ interface; IR vibrational modes related to chemical bonding in a-Si: $\mathrm{H}$ and $\mathrm{ZnO}$; and free carrier absorption in $\mathrm{Ag}$ and the $\mathrm{Ag}+\mathrm{ZnO}$ interface have been obtained from spectra in $\varepsilon$. In addition to information on each of these materials in the $n-i-p$ device structure, the structural and optical properties derived here can be applied in the future analysis of ex situ SE in either single spot [36] or mapping configurations.

\section{Experimental Details}

Thin film doped and undoped Si:H films were deposited using a load-locked $\mathrm{rf}(13.56 \mathrm{MHz})$ PECVD reactor onto $6 " \times 6$ " borosilicate glass substrates coated with $\mathrm{rf}$ magnetron sputtered $\mathrm{ZnO} / \mathrm{Ag}$ BRs as are commonly used in $n-i-p$ configuration solar cells. Si:H $n-, p-$, and $i$-layers have been prepared using different hydrogen dilution ratios, $R$, onto BR coated substrates or those otherwise mimicking the outermost previous layer in the device structure to generate growth evolution diagrams and identify the optimum conditions for protocrystalline a-Si:H for solar cells. Table 1 lists the deposition parameters used for fabrication of each layer including gas flows, pressure $(p)$, power density $(P)$, and substrate temperature $(T)$. The deposition conditions used here were adopted from the Dahal et al., 2013 and Dahal et al., 2014 [23,37]. The deposition was done in the same chamber corresponding to reasonable device quality materials as evidenced by incorporation in $n-i-p$ solar cells without textured BRs yielding $~ 7.5 \%$ efficiency. Maximum device performance parameters are open circuit voltage of $0.90 \mathrm{~V}$, short circuit current of $12.5 \mathrm{~mA} / \mathrm{cm}^{2}$, and fill factor of $70 \%$. The open circuit voltage and fill factor are reasonable for moderate quality $n-i-p$ solar cells. The short circuit current is low as the specular BR does not produce the level of scattering expected from a textured BR where the optical path length of long wavelength light not initially absorbed in the intrinsic a-Si:H layer is increased. This increase in optical path length results in increased current density, which is absent for specular devices. The $n$-type Si:H films were deposited onto BR coated borosilicate glass. The intrinsic layers 
were deposited onto BR's coated with $n$-type a-Si:H prepared at $R=50$. The $p$-type Si:H films were deposited onto borosilicate glass initially coated with $\sim 3000 \AA$ thick intrinsic a-Si:H prepared at $R=10$. This intrinsic layer is deposited to eliminate any contributions to the microstructural evolution from the underlying glass substrate. Variable parameters were $R=\left[\mathrm{H}_{2}\right] /\left[\mathrm{SiH}_{4}\right]$ for all three layers. The dopant gas ratios for $n^{-}\left(D=\left[\mathrm{PH}_{3}\right] /\left[\mathrm{SiH}_{4}\right]\right)$ and $p$-layers $\left(D=\left[\mathrm{B}_{2} \mathrm{H}_{6}\right] /\left[\mathrm{SiH}_{4}\right]\right)$, which can have significant influence on structural and the electronic properties, were fixed at $D=0.0125$. $\mathrm{Cr}, \mathrm{Ag}$, and $\mathrm{ZnO}$ layers were prepared by rf magnetron sputtering at room temperature. Here, $\mathrm{Cr}$ was used as an adhesion interlayer to avoid delamination of the Ag film from the borosilicate glass. The $\mathrm{ZnO} / \mathrm{Ag} \mathrm{BR}$ structures were prepared under identical conditions for each sample to study how the Si:H layers grow in the device configuration.

Table 1. Deposition conditions for the individual layers in the a-Si:H $n-i-p$ solar cell configuration deposited on 6" $\times 6$ " borosilicate glass substrates. The $5 \%$ dopant gas in $\mathrm{H}_{2}$ is by volume. $\mathrm{Cr}, \mathrm{Ag}$, and $\mathrm{ZnO}$ were sputtered at room temperature (RT).

\begin{tabular}{|c|c|c|c|c|c|c|c|c|}
\hline \multirow{2}{*}{ Layer } & \multirow{2}{*}{$\begin{array}{c}\text { Substrate } \\
\text { Temperature } \\
\text { T }\left({ }^{\circ} \mathrm{C}\right)\end{array}$} & \multirow{2}{*}{$\begin{array}{l}\text { Pressure } \\
\text { p } \\
\text { (mTorr) }\end{array}$} & \multirow{2}{*}{$\begin{array}{c}\text { Radio } \\
\text { Frequency (rf) } \\
\text { Power } P\left(W / \mathrm{cm}^{2}\right)\end{array}$} & \multicolumn{5}{|c|}{ Gas Flow (sccm) } \\
\hline & & & & Ar & $\mathrm{SiH}_{4}$ & $\begin{array}{c}5 \% \mathrm{PH}_{3} \text { or } \\
\mathrm{B}_{2} \mathrm{H}_{6} \text { in } \mathrm{H}_{2}\end{array}$ & $\mathbf{H}_{2}$ & $R=\left[\mathrm{H}_{2}\right] /\left[\mathrm{SiH}_{4}\right]$ \\
\hline $\mathrm{Cr}$ & RT & 5 & 0.92 & 10 & - & - & - & - \\
\hline $\mathrm{Ag}$ & RT & 5 & 0.92 & 10 & - & - & - & - \\
\hline $\mathrm{ZnO}$ & RT & 5 & 0.92 & 10 & - & - & - & - \\
\hline$n$ & 200 & 1500 & 0.032 & - & 2 & $0.5 \mathrm{PH}_{3}$ & $40-160$ & $20-80$ \\
\hline$i$ & 200 & 800 & 0.04 & - & 5 & - & $50-250$ & $10-50$ \\
\hline$p$ & 100 & 1500 & 0.066 & - & 2 & $0.5 \mathrm{~B}_{2} \mathrm{H}_{6}$ & $100-400$ & $50-200$ \\
\hline
\end{tabular}

RTSE was performed in situ at a single spot during deposition using a rotating-compensator multichannel ellipsometer (J. A. Woollam Company model M-2000) that can measure ellipsometric spectra (in the form of $N=\cos 2 \psi, C=\sin 2 \psi \cos \Delta, S=\sin 2 \psi \sin \Delta$ ) from 0.734 to $5.88 \mathrm{eV}$ with a minimum data acquisition time of $50 \mathrm{~ms}$ [38,39]. This type of instrument collects ellipsometric spectra at all photon energies in parallel by a combination of a 1-D linear detector array and serial pixel readout. Dual detectors are required to access this spectral range, and consist of a silicon based charged coupled device (CCD) and indium gallium arsenide photodiode array (PDA). RTSE measurements were collected at the respective deposition temperature at angles of incidence near $70^{\circ}$ and spectra obtained from single optical cycles were averaged over $1.5 \mathrm{~s}$ intervals to increase the signal-to-noise ratio. Analysis of experimentally collected RTSE data was performed using J. A. Woollam Co. CompleteEASE software (Lincoln, NE, USA). The time evolution of $d_{b}$ and $d_{s}$ as well as the spectroscopic $\varepsilon$ of the bulk Si:H layers were extracted from RTSE data using a global $\Sigma \sigma$-minimization procedure. For Si:H films, global $\Sigma \sigma$-minimization analysis of RTSE involves using test $d_{b}$ and $d_{s}$ values for the Si:H layer being deposited on top of a pre-defined substrate stack to numerically solve for test $\varepsilon$ of the Si:H layer [29]. The test values of $\varepsilon$ are then used to fit other spectra collected at different times when the film is relatively homogeneous, typically near 100-200 $\AA$ in accumulated material thickness for $\mathrm{Si}: \mathrm{H}$ films where structural transitions have not yet had time to mature. The approach is applied in the regime prior to crystallite nucleation and is iterated in order to obtain numerically inverted $\varepsilon$ yielding the lowest spectrally and time-averaged error, $\sigma$, over the multiple time measurements selected. The numerically inverted $\varepsilon$ minimizing $\sigma$ are taken to be the best representation of the a-Si:H optical properties and are then used to determine structural parameter variations over the full set of RTSE data, with the nucleation of crystallites from the a-Si:H matrix identified by a sharp increase in the surface roughness thickness ( $\geqslant 1 \AA$ between successive time points) and by increases in $\sigma$ as spectra 
in $\varepsilon$ for a-Si:H are no longer adequate to fit ellipsometric spectra collected as nanocrystallites evolve. The unweighted error function, $\sigma$, is defined by [40]:

$$
\sigma=\sqrt{\frac{1}{3 N-M} \sum_{j=1}^{N}\left[\begin{array}{c}
\left(\cos 2 \psi_{j}^{\bmod }-\cos 2 \psi_{j}^{\exp }\right)^{2} \\
+\left(\sin 2 \psi_{j}^{\bmod } \cos \Delta_{j}^{\bmod }-\sin 2 \psi_{j}^{\exp } \cos \Delta_{j}^{\exp }\right)^{2} \\
+\left(\sin 2 \psi_{j}^{\bmod } \sin \Delta_{j}^{\bmod }-\sin 2 \psi_{j}^{\exp } \sin \Delta_{j}^{\exp }\right)^{2}
\end{array}\right]}
$$

where $N$ is the number of measured values; and $M$ the number of fit parameters; "exp" denotes experimental spectra; and "mod" denotes that generated from the model. An advantage of conducting in situ RTSE measurements during growth of Si:H by PECVD is that spectra in $\varepsilon$ can be obtained prior to the exposure of the sample to ambient and potential oxidation.

Near IR to near UV room temperature ellipsometric spectra over a range from 0.734 to $5.88 \mathrm{eV}$ were collected at a single spot ex situ prior to the collection of the ex situ IR-SE data as those measurements were not able to be collected in situ during film growth. IR-SE data was collected at a single spot using a similar single rotating compensator instrument (J. A. Woollam Company, Lincoln, NE, USA, model FTIR-VASE) from 0.04 to $0.75 \mathrm{eV}$ at $1 \mathrm{~cm}^{-1}$ resolution [41]. The angle of incidence for all ex situ measurements was nominally $70^{\circ}$. Ellipsometric spectra over the mid-IR to near UV range collected from the two instruments were analyzed simultaneously using a common parameterization for $\varepsilon$ based on structural models initially developed from RTSE and near IR to near UV measurements and J. A. Woollam Co. WVASE software (Lincoln, NE, USA). The error function in Equation 1 is also used for analysis and fitting of ex situ IR-SE data.

For in situ RTSE, ex situ near IR to UV SE, and ex situ IR-extended SE data analysis, the optical response of the surface roughness layer of thickness $d_{s}$ for $\mathrm{Si}: \mathrm{H}$ and $\mathrm{ZnO}$ is represented using Bruggeman effective $[42,43]$ medium approximation mathematically represented as:

$$
\sum_{n} f_{n} \frac{\varepsilon_{n}-\varepsilon}{\varepsilon_{n}+2 \varepsilon}=0 .
$$

in this expression, material fractions $\left(f_{n}\right)$ and component material optical response $\left(\varepsilon_{n}\right)$ are used to generate a composite $\varepsilon$ for the mixture. For surface roughness in this work, spectra in $\varepsilon$ from Bruggeman effective medium approximation consist of 0.5 void and 0.5 underlying material volume fractions, regardless of composition of the underlying layer.

The structural model constructed for each sample consists of a stratified layer stack of optically distinct materials, which may be continuous films, interfaces with unique $\varepsilon$ and thickness, or Bruggeman effective medium approximation layers. Ellipsometric spectra are modeled using a scattering matrix formalism [44] in which $2 \times 2$ matrices based on Fresnel coefficients and wave propagation of light through media is generated for the semi-infinite substrate and ambient, each layer of finite thickness, and the interfaces between each optically distinct layer. Matrices are calculated for the components of the incident electric field both parallel and perpendicular to the plane of incidence. In general, ellipsometric spectra are sensitive to spectra in $\varepsilon$ for each material, including the ambient and substrate, and the thicknesses of optically finite layers.

\section{Results and Discussion}

\subsection{Optical Characterization of Back Reflector Components and Structure}

The first layers deposited for $n-i-p$ configuration a-Si:H solar cells comprise the $\mathrm{ZnO} / \mathrm{Ag}$ BR structure. Therefore, ellipsometric spectra from 0.04 to $5.0 \mathrm{eV}$ are collected and analyzed for a $\mathrm{ZnO} / \mathrm{Ag}$ BR structure. The models and thicknesses described here first correspond to a $\mathrm{ZnO}$ coated Ag BR sample, while variations in properties due to growth of over-deposited $n$ - and $i$-type a-Si:H layers is described in Section 3.3.1. All layers were deposited without vacuum break with conditions given in 
Table 1. In situ SE data from $0.734 \mathrm{eV}$ to $5.88 \mathrm{eV}$ was collected for each deposited layer and the model generated was used for extended spectral range IR-SE analysis.

\subsection{1. $\mathrm{Ag}$ and $\mathrm{ZnO}+\mathrm{Ag}$ Interface Properties}

Data collected for semi-infinite Ag substrate were taken before $\mathrm{ZnO}$ layer deposition at room temperature and were analyzed in the energy range from 0.734 to $5.88 \mathrm{eV}$. Figure 1 shows spectra in $\varepsilon$ for Ag parameterized by a combination of a Drude oscillator [45], a higher energy transition assuming critical point parabolic bands (CPPB) [46], and a constant additive term to $\varepsilon_{1}$ denoted as $\varepsilon_{\infty}$. The surface roughness is represented by two Lorentz oscillators [47] with $\varepsilon_{\infty}=1$. The Drude oscillator is represented by:

$$
\varepsilon(E)=\frac{-\hbar^{2}}{\varepsilon_{0} \rho\left(\tau E^{2}+i \hbar E\right)}
$$

where $\hbar$ is the reduced Planck's constant, $\varepsilon_{0}$ is the permittivity of free space, $\tau$ is the scattering time, and $\rho$ is the resistivity. Each CPPB oscillator is represented by:

$$
\varepsilon(E)=A e^{i \phi}\left\{\frac{\Gamma}{\left[2 E_{n}-2 E-i \Gamma\right]}\right\}^{\mu}
$$

where $A, E_{n}, \Gamma, \mu$, and $\varphi$ are the amplitude, resonance energy, broadening, exponent, and phase of the critical point, respectively. The exponent $\mu$ can assume the values of $1 / 2,0$, and $-1 / 2$ depending on whether the critical points are one, two, or three dimensional in nature. In this work, only the one dimensional CPPB oscillator has been used, and so its value was fixed at $\mu=0.5$. Each Lorentz oscillator is represented by:

$$
\varepsilon(E)=\frac{A \Gamma E_{0}}{\left[E_{0}^{2}-E^{2}-i \Gamma E\right]}
$$

where $A, \Gamma$, and $E_{0}$ represent amplitude, broadening, and resonance energy respectively. All parameters describing Ag and its surface roughness are listed in Table 2. A resistivity of $3.02 \pm 0.03 \times 10^{-6} \Omega \mathrm{cm}$ and a scattering time of $16.7 \pm 0.1 \mathrm{fs}$ were determined from the Drude oscillator parameters of the Ag film.

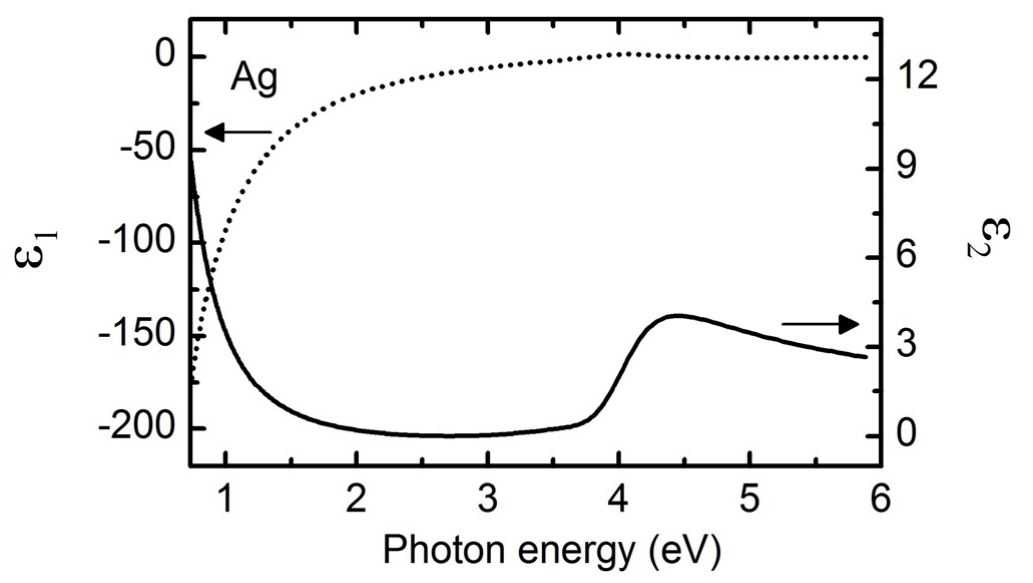

Figure 1. Complex dielectric function spectra, $\varepsilon=\varepsilon_{1}+\mathrm{i} \varepsilon_{2}$, (arrow pointing left for $\varepsilon_{1}$ axis, arrow pointing right for $\varepsilon_{2}$ axis) from 0.734 to $5.88 \mathrm{eV}$ for a semi-infinite $\mathrm{Ag}$ film parameterized with a combination of a Drude oscillator and two oscillators assuming critical point parabolic bands (CPPB) with parameters listed in Table 2. 
Table 2. Parameters describing complex dielectric function $\left(\varepsilon=\varepsilon_{1}+i \varepsilon_{2}\right)$ and structure for a semi-infinite Ag film on a borosilicate glass over coated by $\mathrm{Cr}$ before $\mathrm{ZnO}$ deposition. Experimental ellipsometric spectra were collected in situ after deposition at room temperature in the spectral range from 0.734 to $5.88 \mathrm{eV}$ and fit using least square regression analysis with an unweighted estimator error function, $\sigma=5 \times 10^{-3}$. For bulk Ag, the parameterization of $\varepsilon$ consisted of a Drude oscillator, two oscillators assuming critical point parabolic bands (CPPB), and a constant additive term to $\varepsilon_{1}$ denoted $\varepsilon_{\infty}$. Spectra in $\varepsilon$ for the $30 \pm 2 \AA$ surface roughness layer were parameterized with two Lorentz oscillators and $\varepsilon_{\infty}=1$.

\begin{tabular}{|c|c|c|c|c|c|}
\hline \multicolumn{6}{|c|}{ Ag Surface Roughness } \\
\hline Oscillator & A (Unitless) & $\Gamma(\mathrm{eV})$ & $\mathrm{E}_{0}(\mathrm{eV})$ & - & - \\
\hline Lorentz & $4.2 \pm 0.2$ & $2.5 \pm 0.1$ & $5.17 \pm 0.02$ & - & - \\
\hline Lorentz & $1.0 \pm 0.3$ & $0.06 \pm 0.03$ & $3.61 \pm 0.01$ & - & - \\
\hline \multicolumn{6}{|c|}{ Bulk Ag } \\
\hline Oscillator & A (Unitless) & $\Gamma(\mathrm{eV})$ & $E_{n}(e V)$ & $\Theta$ (degrees) & $\mu$ \\
\hline СРРВ & $5.29 \pm 0.09$ & $0.70 \pm 0.03$ & $3.845 \pm 0.008$ & $-180.306 \pm 0.002$ & 0.5 \\
\hline СРРВ & $10.39 \pm 0.07$ & $0.87 \pm 0.01$ & $4.025 \pm 0.001$ & $-7.0 \pm 0.4$ & 0.5 \\
\hline Drude & \multicolumn{2}{|c|}{$\rho(\Omega \mathrm{cm})$} & & $\tau(\mathrm{fs})$ & \\
\hline Constant additive term to $\varepsilon_{1}$ & \multirow{2}{*}{\multicolumn{2}{|c|}{$3.02 \pm 0.03 \times 10^{-6}$}} & \multicolumn{3}{|c|}{$\begin{array}{c}\tau(\mathbf{t s}) \\
16.7 \pm 0.1\end{array}$} \\
\hline$\varepsilon_{\infty}$ & & & $1.632 \pm 0.008$ & & \\
\hline
\end{tabular}

The structural model for the $\mathrm{ZnO} / \mathrm{Ag} \mathrm{BR}$ in the energy range 0.734 to $5 \mathrm{eV}$ consisted of a semi-infinite Ag metal layer deposited onto glass, a $108 \pm 10 \AA \mathrm{ZnO}+\mathrm{Ag}$ interfacial layer, a $3059 \pm 3 \AA$ bulk $\mathrm{ZnO}$ layer, and a $80 \pm 1 \AA$ surface roughness represented using Bruggeman effective medium approximation of $0.5 \mathrm{ZnO}$ and 0.5 void volume fractions. Parametric expressions were used to describe $\varepsilon$ for $\mathrm{Ag}, \mathrm{ZnO}$, and the $\mathrm{ZnO}+\mathrm{Ag}$ interface and are listed in Tables 2 and 3. Previous studies of $\mathrm{ZnO} / \mathrm{Ag}$ interfaces in the BR of thin film n-i-p a-Si:H PV shows that the optically determined value of Ag surface roughness obtained from RTSE is very close to that measured with atomic force microscope (AFM) with $d_{s, R T S E}(\AA)=0.96 d_{s, A F M}(\AA)+5 \AA$ [28]. The $d_{s, R T S E}=30 \pm 2 \AA$ for Ag corresponds to a $d_{s, A F M}=26 \AA$. After deposition of $\mathrm{ZnO}$, the $\mathrm{ZnO} / \mathrm{Ag}$ interface layer thickness is reported by Dahal et al. as $d_{i}(\AA)=1.98 d_{s}(\AA)+17.5 \AA$. The interface layer thickness predicted from the Ag surface roughness in this work is $76.9 \AA$ as compared to that obtained in our parametric analysis of $108 \AA$ [28]. Our parametric value slightly overestimates the prediction, however in Dahal et al. [28] the samples with similar Ag surface roughness, $25-30 \AA$, also has an interface thickness of 75-110 $\AA$ which are greater than the linear prediction. Figure 2 shows that the spectra in $\varepsilon$ obtained for the $\mathrm{ZnO}+\mathrm{Ag}$ interface is optically different than $\mathrm{Ag}$ and $\mathrm{ZnO}$ alone and can be modeled by a Lorentz oscillator and a Drude oscillator in the near IR to near UV range $(0.734$ to $5 \mathrm{eV})$ with $\varepsilon_{\infty}=1$. The $\mathrm{ZnO}+\mathrm{Ag}$ interface exhibits a clear localized particle plasmon absorption feature which can be modeled using a Lorentz oscillator with a resonance energy at $2.83 \pm 0.01 \mathrm{eV}[27,48]$. A resistivity of $3.7 \pm 0.5 \times 10^{-5} \Omega \mathrm{cm}$ and a scattering time of $2.7 \pm 0.3$ were determined from the Drude oscillator parameters of the $\mathrm{ZnO}+\mathrm{Ag}$ interface. These values indicate that when compared to bulk $\mathrm{Ag}$, the interface is less conductive due to incorporation of higher resistivity undoped $\mathrm{ZnO}$ and potentially more disordered as suggested by the lower scattering time. Over this spectral range, $\varepsilon$ for $\mathrm{ZnO}$ was initially fit using two CPPB oscillators, $\varepsilon_{\infty}$, and a zero-broadened Sellmeier oscillator [49] represented by:

$$
\varepsilon(E)=\frac{A}{\left(E_{n}^{2}-E^{2}\right)}
$$

where $A$ and $E_{n}$ represent the amplitude and resonance energy, respectively. 


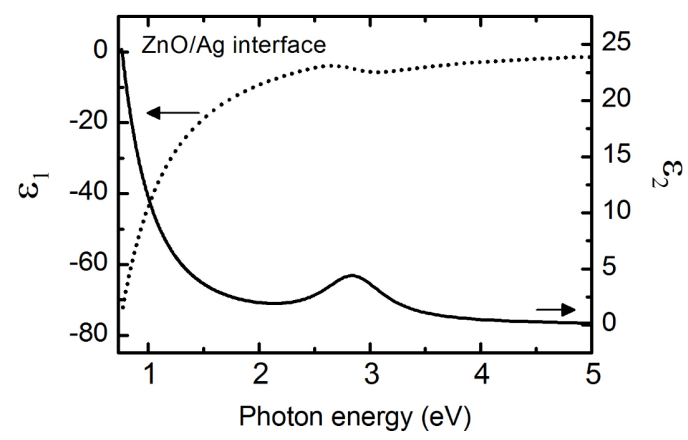

Figure 2. Spectra in $\varepsilon$ (arrow pointing left for $\varepsilon_{1}$ axis, arrow pointing right for $\varepsilon_{2}$ axis) from 0.734 to $5.0 \mathrm{eV}$ for the $108 \pm 1 \AA$ thick $\mathrm{ZnO}+\mathrm{Ag}$ interface layer parameterized with a Lorentz and a Drude oscillator with parameters listed in Table 3.

Table 3. Parameters describing $\varepsilon$ and structure for a $\mathrm{ZnO}$ film deposited on $\mathrm{Ag}$ and the $\mathrm{ZnO}+\mathrm{Ag}$ interface formed. Experimental ellipsometric spectra were collected in situ after deposition at room temperature in the spectral range from 0.734 to $5.0 \mathrm{eV}$ and fit using least squares regression analysis with an unweighted estimator error function, $\sigma=7 \times 10^{-3}$. Parameters describing $\varepsilon$ for Ag were fixed from Table 2. For $\mathrm{ZnO}$, the parameterization of $\varepsilon$ consisted of two CPPB oscillators, a Sellmeier oscillator, and $\varepsilon_{\infty}$. For the $\mathrm{ZnO}+\mathrm{Ag}$ interface, the parameterization of $\varepsilon$ consisted of a Drude oscillator, a Lorentz oscillator, and $\varepsilon_{\infty}$.

\begin{tabular}{|c|c|c|c|c|}
\hline Layer & \multicolumn{4}{|c|}{ Oscillators } \\
\hline \multirow{6}{*}{$\begin{array}{c}\mathrm{ZnO} \\
d_{b}=3060 \pm 3 \AA \\
d_{s}=80 \pm 1 \AA\end{array}$} & \multicolumn{2}{|r|}{$\mathrm{CPPB}(\mu=0.5)$} & \multicolumn{2}{|c|}{$\varepsilon_{\infty}=2.27 \pm 0.01$} \\
\hline & A (Unitless) & $\Gamma(\mathrm{eV})$ & $\mathrm{E}_{\mathrm{n}}(\mathrm{eV})$ & $\Theta$ (degrees) \\
\hline & $\begin{array}{l}2.63 \pm 0.02 \\
1.41 \pm 0.02\end{array}$ & $\begin{array}{c}0.199 \pm 0.002 \\
3.83 \pm 0.08\end{array}$ & $\begin{array}{c}3.363 \pm 0.001 \\
4.36 \pm 0.03\end{array}$ & $\begin{array}{c}-20.1 \pm 0.5 \\
0 \text { (fixed) }\end{array}$ \\
\hline & \multicolumn{4}{|c|}{ Sellmeier } \\
\hline & $\mathrm{A}\left(\mathrm{eV}^{2}\right)$ & \multicolumn{2}{|c|}{$\Gamma(\mathrm{eV})$} & $E_{n}(e V)$ \\
\hline & $0.080 \pm 0.002$ & \multicolumn{2}{|c|}{-} & 0 \\
\hline \multirow{6}{*}{$\begin{array}{c}\mathrm{ZnO} / \mathrm{Ag} \\
\text { Interface }=108 \pm 11 \AA\end{array}$} & \multicolumn{4}{|c|}{ Lorentz $\quad \varepsilon_{\infty}=1$} \\
\hline & A (Unitless) & \multicolumn{2}{|c|}{$\Gamma(\mathrm{eV})$} & $\mathrm{E}_{0}(\mathrm{eV})$ \\
\hline & $2.8 \pm 0.2$ & \multicolumn{2}{|c|}{$0.57 \pm 0.05$} & $2.83 \pm 0.01$ \\
\hline & \multicolumn{4}{|c|}{ Drude } \\
\hline & \multicolumn{2}{|c|}{$\rho(\Omega \mathrm{cm})$} & \multicolumn{2}{|c|}{$\tau(\mathrm{fs})$} \\
\hline & \multicolumn{2}{|c|}{$3.7 \pm 0.5 \times 10^{-5}$} & \multicolumn{2}{|c|}{$2.7 \pm 0.3$} \\
\hline
\end{tabular}

\subsubsection{Phonon Modes in $\mathrm{ZnO}$}

The analysis was extended to the IR by fitting parameters defining $\varepsilon$ for $\mathrm{ZnO}$ only and fixing those defining $\varepsilon$ for $\mathrm{Ag}$ and the $\mathrm{ZnO}+\mathrm{Ag}$ interface as well as the interface layer thickness. This analysis approach was chosen because free carrier absorption represented by the Drude feature dominates the IR response of $\mathrm{Ag}$ and the $\mathrm{ZnO}+\mathrm{Ag}$ interface layers and is already established from near IR to UV spectral range analysis. A common parameterization of $\varepsilon$ for the $\mathrm{ZnO}$ was applied for the data collected from the two instruments with spectral ranges from 0.04 to $0.734 \mathrm{eV}$ and 0.734 to $5.0 \mathrm{eV}$, respectively, although the bulk $\mathrm{ZnO}$ layer thickness was allowed to vary for the ellipsometric spectra collected from each respective instrument to account for measurement on different spots over the sample surface. A common surface roughness thickness between the two sets of measured spectra was obtained, as this effect will vary less with non-uniformity than the overall bulk layer thickness. Figure 3 shows $\varepsilon$ for $\mathrm{ZnO}$ represented by a combination of CPPB oscillators for electronic transitions, Lorentz oscillators representing IR phonon modes, and a constant real additive term $\varepsilon_{\infty}$ to account for dispersion from absorption features outside the measured spectral range from 0.04 to $5 \mathrm{eV}$ with parameters given in Table 4 . The near IR to near UV range shows only small absorption below the lowest direct transition at 
$3.364 \mathrm{eV}$ as expected for direct band gap $\mathrm{ZnO}$ [50]. Phonon modes for wurtzite $\mathrm{ZnO}$ are $\Gamma_{\mathrm{opt}}=1 \mathrm{~A}_{1}+2 \mathrm{~B}_{1}$ $+1 E_{1}+2 E_{2}$, with $A_{1}$ and $E_{1}$ modes IR-active. Only one characteristic transverse optical (TO) mode for $\mathrm{ZnO}$ with $\mathrm{E}_{1}$ symmetry at $0.0501 \mathrm{eV}\left(404.08 \mathrm{~cm}^{-1}\right)$ is resolved for this sample [51-53]. Weak absorption bands in the spectral region from 0.134 to $0.264 \mathrm{eV}\left(1080\right.$ to $\left.2130 \mathrm{~cm}^{-1}\right)$ have been observed and are often associated with hydrogen-associated bending modes; stretching modes of hydrogen bonded to heavier elements like zinc; and various carbon, oxygen, and nitrogen-related stretching modes not involving hydrogen [54]. These types of peaks are analogous to those found in the absorbance spectra from traditional unpolarized FTIR measurements, which lack sensitivity to discerning thickness and the full complex optical properties simultaneously—a capability of SE measurements.

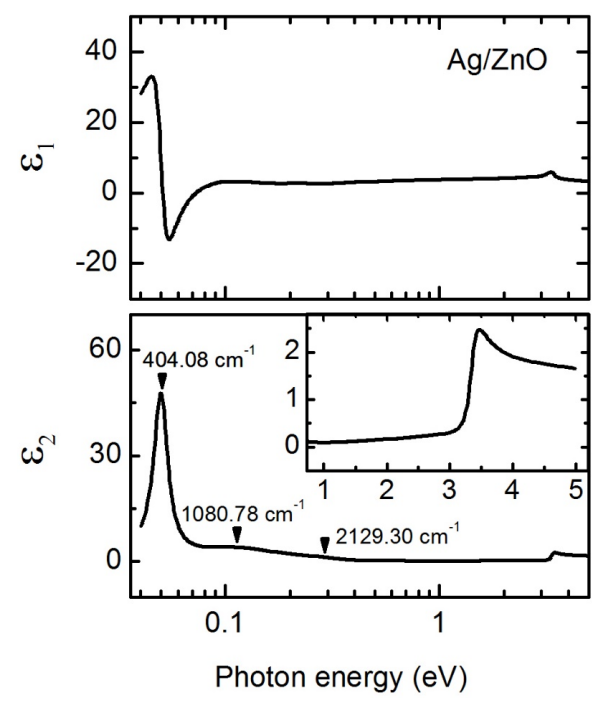

Figure 3. Spectra in $\varepsilon$ (top panel, real part $\varepsilon_{1}$; bottom panel, imaginary part $\varepsilon_{2}$ ) from 0.04 to $5.0 \mathrm{eV}$ for a $3010 \pm 2 \AA$ thick $\mathrm{ZnO}$ film on $\mathrm{Ag}$, with $\varepsilon$ for $\mathrm{ZnO}$ parameterized using a combination of two CPPB and three Lorentz oscillators with parameters listed in Table 4. The inset shows high-energy electronic transitions in $\varepsilon_{2}$.

Table 4. Parameters describing $\varepsilon$ and structure for a $\mathrm{ZnO}$ film deposited in a $\mathrm{ZnO} / \mathrm{Ag}$ back reflector (BR). Experimental ellipsometric spectra were collected ex situ using near infrared to ultraviolet $(0.734$ to $5.0 \mathrm{eV})$ and infrared $(0.04$ to $0.734 \mathrm{eV})$ spectral range instruments and fit jointly using least squares regression analysis with an unweighted estimator error function, $\sigma=8 \times 10^{-3}$. Parameters describing $\varepsilon$ for $\mathrm{Ag}$ and the $\mathrm{ZnO}+\mathrm{Ag}$ interface were fixed from Tables 2 and 3 respectively. The $\mathrm{ZnO}$ bulk layer thickness was allowed to vary separately for each set of ellipsometric spectra; all other parameters are common to both analyses. For $\mathrm{ZnO}$, the parameterization of $\varepsilon$ consisted of two CPPB oscillators, three Lorentz oscillators, and $\varepsilon_{\infty}$.

\begin{tabular}{|c|c|c|c|c|}
\hline Layer & \multicolumn{4}{|c|}{ Oscillators } \\
\hline \multirow{7}{*}{$\begin{array}{c}\mathrm{ZnO} \\
d_{b}(\text { Near IR to UV) }=2996 \pm 2 \AA \\
d_{b}(\mathrm{IR})=3025 \pm 2 \AA \\
d_{s}=84 \pm 1 \AA\end{array}$} & & $\mathrm{CPPB}(\mu=0.5)$ & $\varepsilon_{\infty}=2.43 \pm 0.01$ & \\
\hline & A (Unitless) & $\Gamma(\mathrm{eV})$ & $E_{n}(e V)$ & $\Theta$ (degrees) \\
\hline & $\begin{array}{l}2.82 \pm 0.02 \\
1.23 \pm 0.02\end{array}$ & $\begin{array}{c}0.209 \pm 0.002 \\
3.95 \pm 0.03\end{array}$ & $\begin{array}{c}3.364 \pm 0.001 \\
3.94 \pm 0.02\end{array}$ & $\begin{array}{c}-20.8 \pm 0.4 \\
0\end{array}$ \\
\hline & \multicolumn{4}{|c|}{ Lorentz } \\
\hline & $0.75 \pm 0.05$ & $0.196 \pm 0.005$ & $0.264 \pm 0.002$ & - \\
\hline & $3.17 \pm 0.03$ & $0.169 \pm 0.007$ & $0.134 \pm 0.001$ & - \\
\hline & $46 \pm 2$ & $0.0093 \pm 0.0004$ & $0.0501 \pm 0.0002$ & - \\
\hline
\end{tabular}

\subsection{RTSE Monitoring of Si:H in n-i-p Solar Cell Devices}

The films used to develop growth evolution diagrams for doped and undoped Si:H deposited in the glass substrate/BR/n-i- $p$ a-Si:H device configuration were grown as a function of $R$ in an effort to probe the subtle fluctuations expected as the material transitions from amorphous to nanocrystalline [31,55]. A distinct type of roughening transition is reported in which crystallites 
nucleate from the growing amorphous phase. Because of the low crystallite nucleation density as observed by Fujiwara et al. and Ferlauto et al. [4,31], the growth of crystalline protrusions produce a roughness layer that increases promptly when compared to increases in bulk layer thickness. Thus, the onset of roughening identifies a transition to mixed-phase amorphous+nanocrystalline (a+nc)-Si:H film growth accompanied by changes in the film optical properties. This behavior denotes the amorphous-to-mixed-phase $[\mathrm{a} \rightarrow(\mathrm{a}+\mathrm{nc})]$ transition. Simple roughening of the amorphous phase also tends to exhibit a lower increase in $d_{s}$, accompanied by only minimal increases in $\sigma$, with accumulated bulk layer thickness. Crystallites nucleating from the amorphous phase grow preferentially over the surrounding material, until the point at which the crystallites cover the surface. The disappearance of the amorphous phase and coalescence of crystallites is denoted as the mixed-phase-to-single-phase nanocrystalline $[(\mathrm{a}+\mathrm{nc}) \rightarrow \mathrm{nc}]$ transition. The $\mathrm{a} \rightarrow(\mathrm{a}+\mathrm{nc})$ and $(\mathrm{a}+\mathrm{nc}) \rightarrow \mathrm{nc}$ transitions were detected using RTSE monitoring and data analysis in this work. The Si:H films prepared at low $R$ remain in the amorphous growth regime throughout the deposited thickness. VIA was applied to RTSE data collected during growth for $\mathrm{Si}: \mathrm{H}$ transitioning from amorphous to nanocrystalline [31,56,57].

Figure 4 shows an example of the results of VIA applied to RTSE data to obtain the surface roughness thickness, nanocrystallite fraction, void fraction, and average mean square error (Equation (1)) as functions of the bulk layer thickness for a $R=50 i$-layer on a BR over-coated with a $200 \AA$ $R=50 n$-layer. The VIA applied here utilizes spectra from 2.75 to $5.0 \mathrm{eV}$ and $\varepsilon$ for a-Si:H and nc-Si:H components as shown in Figure 5. Spectra in $\varepsilon$ for nc-Si:H was obtained from the end of the respective deposition when the film is known to be fully nanocrystalline, $\sim 1150 \AA$ of a $1300 \AA$ thick film using the same optical model as was used for the $i$-layer growth evolution diagram. In this model the free parameters are $d_{b}$ and $d_{s}$. Spectra in $\varepsilon$ for the amorphous phase was taken from the analysis of $R=15$ deposition corresponding to a time within the first $\sim 200 \AA$ of bulk material prior to the nucleation of nanocrystallites. There is strong optical contrast between the two sets of $\varepsilon$ for $\mathrm{Si}: \mathrm{H}$, in that the amorphous phase has only a single broad resonance while that of nanocrystallite material has two features representative of dampened and broadened critical point features found in single crystal silicon [58]. These reference spectra in $\varepsilon$ for a-Si:H and nc-Si:H, along with that for void $(\varepsilon=1)$, were then used in a three component Bruggeman effective medium approximation [42,43] layer and a least-squares regression within the VIA with $d_{s}$ and the relative nanocrystallite $\left(f_{n c}\right)$ and void $\left(f_{\text {void }}\right)$ fractions as free parameters and the amorphous fraction constrained $\left(f_{a}=1-f_{n c}-f_{v o i d}\right)$.

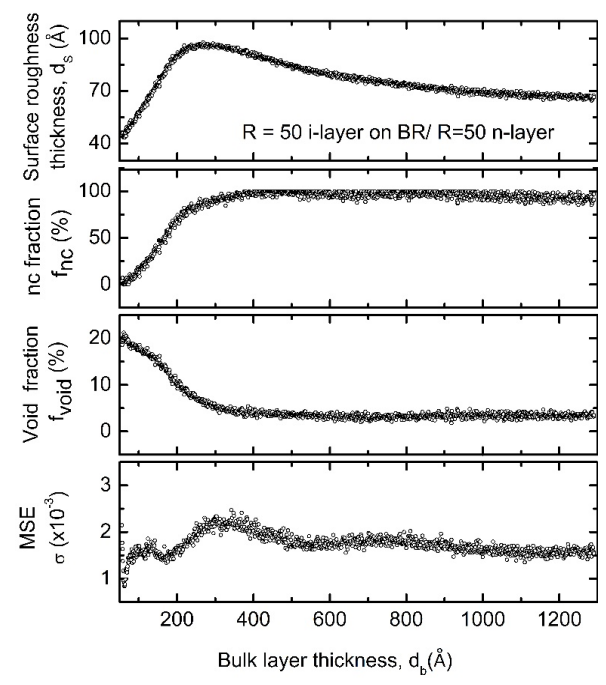

Figure 4. Mean square error (MSE), void fraction $\left(f_{\text {void }}\right)$, nanocrystalline volume fraction $\left(f_{n c}\right)$, and surface roughness thickness $\left(d_{s}\right)$ in the top $\sim 10 \AA$ of the bulk layer, plotted versus the accumulated bulk layer thickness for an intrinsic hydrogen diluted $R=\left[\mathrm{H}_{2}\right] /\left[\mathrm{SiH}_{4}\right]=50 \mathrm{Si}: \mathrm{H}$ film deposited on a $200 \AA R=50 n$-type a-Si:H over-deposited onto a $\mathrm{ZnO} / \mathrm{Ag}$ back reflector (BR), as determined by virtual interface analysis (VIA) applied to real time spectroscopic ellipsometry (RTSE) data. Spectrally averaged mean error for $f_{\text {void }}, f_{n c}$, and $d_{s}$ are $0.3 \%, 2.4 \%$, and $0.8 \AA$ A respectively. 


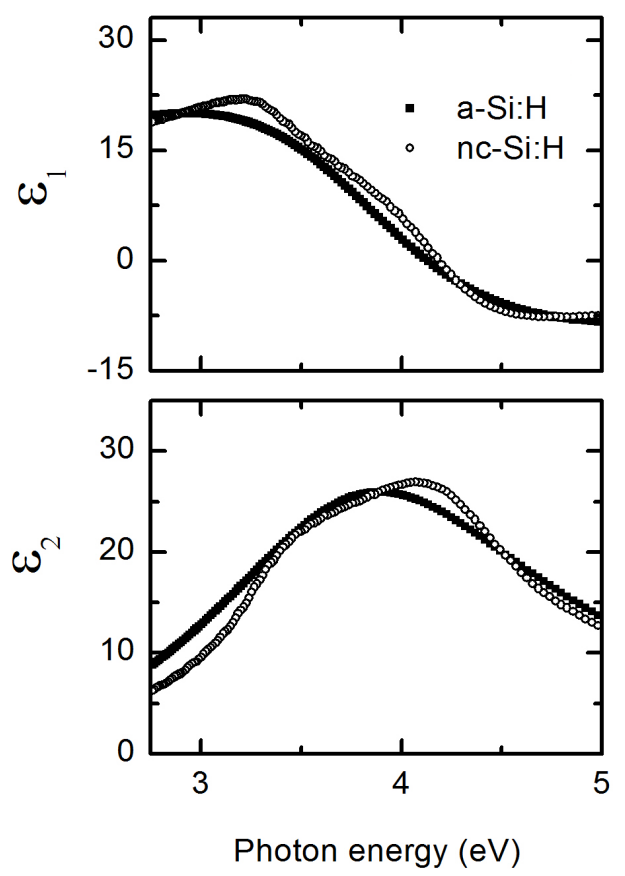

Figure 5. Spectra in $\varepsilon$ (top panel, real part $\varepsilon_{1}$; bottom panel, imaginary part $\varepsilon_{2}$ ) of a-Si:H and nc-Si:H reference material used in VIA applied over a spectral range from 2.75 to $5.0 \mathrm{eV}$. Spectra in $\varepsilon$ for a-Si:H and nc-Si:H were obtained from analysis of RTSE data and by numerical inversion at a bulk layer thickness of 200 and $1150 \AA$, respectively.

Results of VIA show an increase in surface roughness followed by a decrease within the first $\sim 300 \AA$ of material accumulation, indicating crystallite nucleation on the substrate followed by coalesce of the clusters. The nanocrystallite fraction increases with bulk layer thickness, then converges to 1.0 as expected for a nanocrystalline film. Voids initially appear with the nucleation of crystallites, which then subsequently decrease and stabilize near $f_{\text {void }}=0.04$ throughout the growth of this layer. Depending on the source of reference $\varepsilon$ for $\mathrm{nc}-\mathrm{Si}: \mathrm{H}$, this behavior could indicate that the grains under these conditions were not well passivated with a-Si:H as is desirable in nc-Si:H PV [22,59]. Optimized nanocrystalline/microcrystalline PV devices often incorporate layers prepared at lowest hydrogen dilution where crystallite growth can occur, and nc-Si:H layers are often fabricated using hydrogen dilution grading approaches to manipulate the degree of crystallinity. For very high values of hydrogen dilution, such as $R=50$ in this example, the material is likely not optimized for solar cells, because cracks related to voids can promote shunts in the cells and channels by which contamination (e.g., oxygen) can enter into the layer $[14,21,60]$.

Comparison of the structural behavior of the $\mathrm{a} \rightarrow(\mathrm{a}+\mathrm{nc})$ and $(\mathrm{a}+\mathrm{nc}) \rightarrow \mathrm{nc}$ transitions as a function of single deposition parameters has been used to produce so-called deposition phase diagrams or growth evolution diagrams which have helped guide the development of optimization principles in Si:H based PV. For example, the structural evolution can be controlled by the dilution of reactive silicon carrying gases with hydrogen during the deposition process. Films prepared at low $R$ remain amorphous throughout their total thickness, while those prepared at higher $R$ nucleate crystallites. The thickness at which the $\mathrm{a} \rightarrow(\mathrm{a}+\mathrm{nc})$ transition occurs decreases with increasing $R$. Optimum a-Si:H based PV devices incorporate layers prepared at the highest $R$ that will remain amorphous throughout the full thickness of the absorber layer while optimum nc-Si:H PV incorporates layers prepared at the lowest $R$ where crystallite growth can occur [7,59-62]. For the case of a-Si:H, the additional hydrogen dilution improves ordering in the a-Si:H network, while for nc-Si:H low hydrogen dilution ensures that hydrogen etching does not occur and the grain boundaries remain well-passivated. 
The growth evolution diagrams of $n$-type, intrinsic, and $p$-type Si:H layers in the $n$-i-p/BR/glass configuration are depicted in Figure 6 . The $n$-type Si:H layers are prepared at $T=200^{\circ} \mathrm{C}, p=1.5 \mathrm{Torr}$, $P=0.032 \mathrm{~W} / \mathrm{cm}^{2}$, and $D=0.0125$ as a function of $R$ varied from 20 to 80 . For $R<50$ the $n$-layer remains amorphous at least to a thickness of $500 \AA$. At $R=50$ nanocrystallites nucleate in the $n$-type Si:H at about $450 \AA$ of bulk layer thickness. The amorphous material prior to the $\mathrm{a} \rightarrow(\mathrm{a}+\mathrm{nc})$ transition of these depositions is protocrystalline [2]. A $\sim 200 \AA$ thick $n$-layer is typical for $n$-i-p configuration devices, and the best $R$ for optimized $n-i-p$ a-Si:H solar cells with a protocrystalline $n$-layer is identified here as near $R=50$. As $R$ is further increased, nanocrystallites nucleate within the amorphous phase at decreasingly lower thicknesses as indicated by the $a \rightarrow(a+n c)$ transition thicknesses. Films nucleating crystallites and grown to sufficient thickness show the $(a+n c) \rightarrow n c$ transition with crystallites coalescing at similarly decreasing thickness with increasing $R$. The film at $R=60$ nucleates crystallites at $\sim 100 \AA$ and coalescence occurs at $\sim 380 \AA$. These transitions occur much sooner for $R=80$ leading to nanocrystallite formation in the very beginning of the deposition, making it unsuitable for an optimum $n$-type layer in single junction a-Si:H devices.

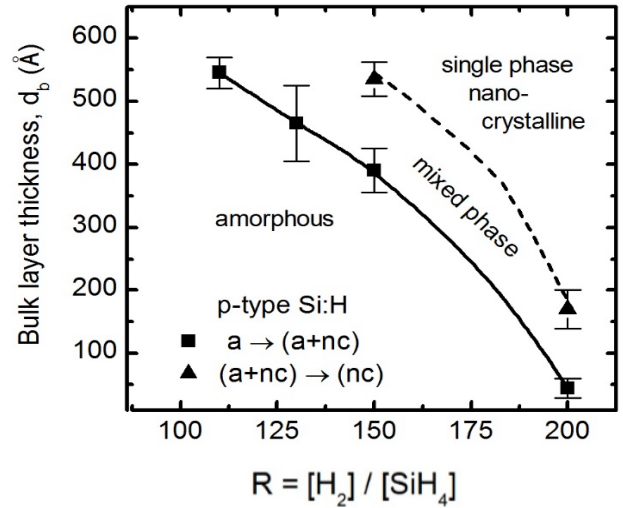

(a)

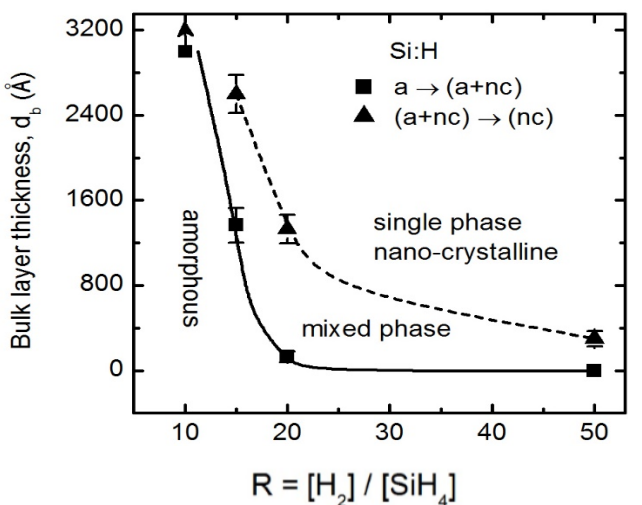

(b)

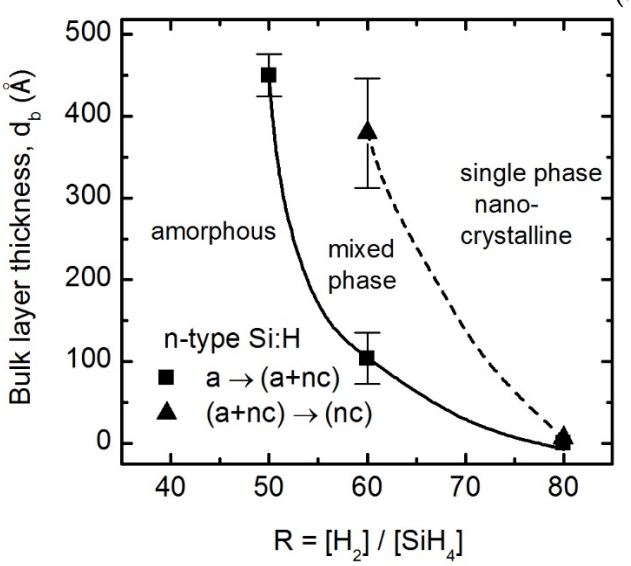

(c)

Figure 6. Growth evolution diagrams obtained from analysis of RTSE data for (a) $p$-type; (b) intrinsic; and (c) $n$-type $\mathrm{Si}: \mathrm{H}$ as a function of variable hydrogen dilution $R=\left[\mathrm{H}_{2}\right] /\left[\mathrm{SiH}_{4}\right]$ in the $n$-i- $p$ solar cell device structure. The data values and connecting lines depict the $\mathrm{a} \rightarrow(\mathrm{a}+\mathrm{nc})$ and $(\mathrm{a}+\mathrm{nc}) \rightarrow \mathrm{nc}$ structural transitions of doped and undoped $\mathrm{Si}: \mathrm{H}$ prepared at conditions described in Table 1. Arrows pointing upward indicate the respective transition occurs beyond the maximum thickness measured.

In both $n-i-p$ substrate and the $p$-i-n superstrate PV device configurations, most incident photons are absorbed in the intrinsic layer with photo-generated electrons and holes transported to the contacts. Hence, optimization of $i$-layer is critical and the optical response and phase composition of these intrinsic layers tremendously impact solar cell performance. The intrinsic Si:H layers are prepared 
at $T=200^{\circ} \mathrm{C}, p=0.8$ Torr, and $P=0.04 \mathrm{~W} / \mathrm{cm}^{2}$ as a function of $R$ varied from 10 to 50 . The growth evolution diagram for intrinsic $\mathrm{Si}: \mathrm{H}$ as a function of variable hydrogen dilution, $10 \leqslant R \leqslant 50$, onto $n$-layer coated BRs has been developed and is shown in Figure 6 . The hydrogen dilution and thickness of $n$-layer was fixed at $R=50$ and $\sim 200 \AA$, based on protocrystallinity observed in the $n$-layer growth evolution diagram. For the intrinsic layer, $R=15$ is the lowest hydrogen dilution ratio at which the $\mathrm{a} \rightarrow(\mathrm{a}+\mathrm{nc})$ transition is observed within $\sim 3000 \AA$ of layer growth. The decrease in the $(\mathrm{a}+\mathrm{nc}) \rightarrow \mathrm{nc}$ thickness with $R$ may indicate higher nucleation density of crystallites for higher hydrogen dilution. Hence, $R=10$ is identified here as optimized for $n-i-p$ a-Si:H solar cells incorporating a $\sim 3000 \AA$ thick protocrystalline absorber [2].

The thickness of the $p$-layer should be thin enough to maximize transparency but thick enough to generate an electric field in the intrinsic layer. Typical $p$-layer thicknesses are $\sim 100-150 \AA$, and a large optical band gap assists in minimizing parasitic absorption of incident light within this layer. Within the amorphous and protocrystalline phase the band gap of the $p$-layer generally increases with increasing $R$. The intrinsic layer, $p$-layer, and their interface are most directly responsible for open circuit voltage optimization, which can be guided using growth evolution diagrams $[63,64]$. The $p$-type Si:H layers are prepared at $T=100^{\circ} \mathrm{C}, p=1.5$ Torr, $P=0.066 \mathrm{~W} / \mathrm{cm}^{2}$, and $D=0.0125$ as a function of $R$ varied from 50 to 200 on borosilicate glass initially coated with $\sim 3000 \AA$ thick intrinsic a-Si:H prepared at $R=10$. From the growth evolution diagram, it can be observed that the $p$-layer depositions with $R>150$ nucleate crystallites within the typical $p$-layer thickness used in a-Si:H based PV. The $R=110$ film grows initially as a-Si:H and the $\mathrm{a} \rightarrow(\mathrm{a}+\mathrm{nc})$ transition occurs after a bulk layer thickness of $545 \AA$ A. Depositions at $50 \leqslant R \leqslant 100$ indicate that this transition occurs for thicknesses greater than the deposited $650 \AA$, which is outside the range of interest for solar cells. At $R=200$, the $\mathrm{a} \rightarrow(\mathrm{a}+\mathrm{nc})$ transition occurs at a bulk thickness of $40 \AA$, and the $(\mathrm{a}+\mathrm{nc}) \rightarrow \mathrm{nc}$ transition occurs within $200 \AA$. The $p$-layer should be deposited at the maximum $R$ that can be sustained without crossing the $a \rightarrow(a+n c)$ transition boundary throughout the desired thickness of 100-150 A here. This $p$-layer growth evolution diagram is comparable to previously published diagrams $[11,12,63,64]$.

The slope of $d_{b}, \mathrm{r}(\mathrm{t})=\mathrm{d}\left(d_{b}(\mathrm{t})\right) / \mathrm{dt}$, was used to determine the deposition rate of each film even though $\varepsilon$ for films containing nanocrystallites are not accurate due to phase evolution with thickness. Figure 7 shows variations in growth rate as functions of $R$ for $n-, i-$, and $p$-layers. The deposition rate shows a familiar trend in that it decreases with increasing $R$. Increased atomic hydrogen present in the plasma resulting from the increase in hydrogen dilution may etch weakly bonded material, leading to the removal of potentially defect-rich material and slowing the deposition rate. These deposition rates were later used in VIA of RTSE data collected for films nucleating crystallites. A schematic diagram showing a single junction $n-i-p$ device with $R$ optimized for the intended thicknesses of each a-Si:H layer is shown in Figure 8.

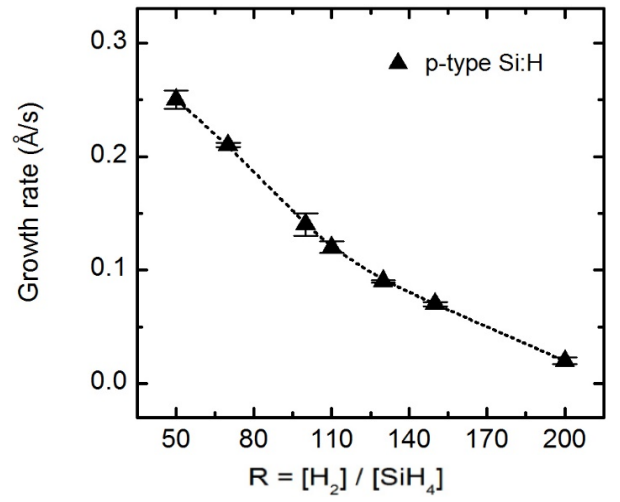

(a)

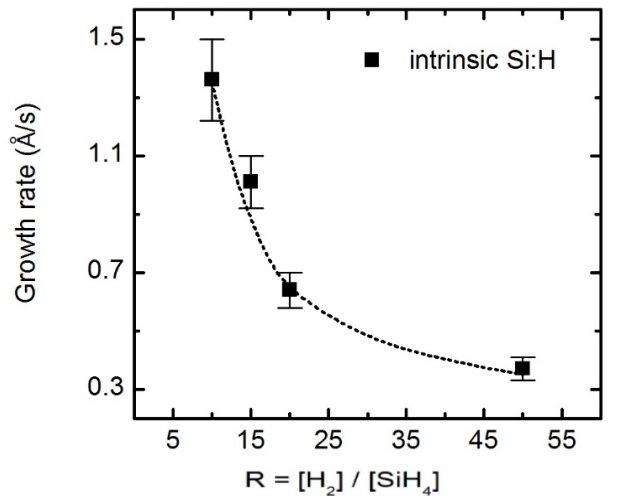

(b)

Figure 7. Cont. 


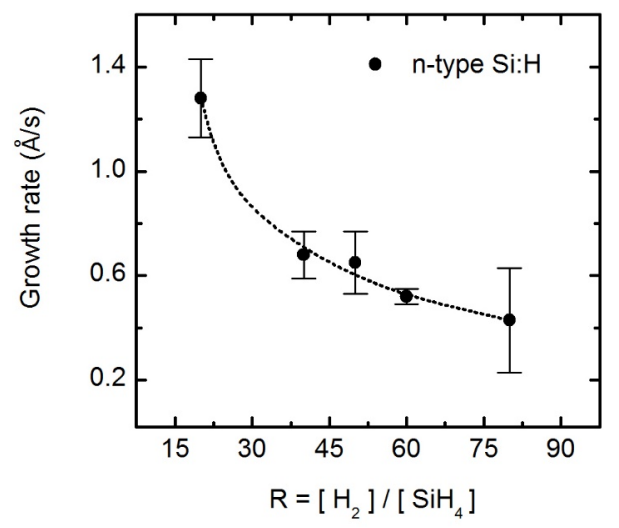

(c)

Figure 7. Deposition rates of (a) $n$-, (b) $i$-, and (c) $p$-layers on $\mathrm{ZnO} / \mathrm{Ag}, n$-layer $/ \mathrm{ZnO} / \mathrm{Ag}$, and $i$-layer/glass, respectively, as functions of $R$.

\begin{tabular}{|c|}
\hline Indium Tin Oxide \\
\hline$p:$ a-Si:H $(R=150-175,100 \AA)$ \\
\hline$i:$ a-Si:H $(R=10,3000 \AA)$ \\
\hline$n:$ a-Si:H $(R=50,200 \AA)$ \\
\hline ZnO $(3000 \AA)$ \\
\hline Ag (Semi-infinite $)$ \\
\hline
\end{tabular}

Figure 8. Schematic of a single junction a-Si:H based solar cell prepared in the $n-i-p$ configuration. Each amorphous or protocrystalline $\mathrm{Si}: \mathrm{H}$ layer is optimized to a value of $R$ with an intended thickness.

\subsection{Ex Situ SE Study of a-Si:H in n-i-p Configuration Solar Cells from the Mid-IR to Near UV}

Ellipsometric spectra from 0.04 to $5.0 \mathrm{eV}$ were collected and analyzed for a $\mathrm{ZnO} / \mathrm{Ag} \mathrm{BR}$ over-coated with intrinsic a-Si:H and $n$-type a-Si:H layers. This $\mathrm{ZnO} / \mathrm{Ag}$ BR sample was over-coated with a-Si:H to determine $\varepsilon$ for a-Si:H over the 0.04 to $5.0 \mathrm{eV}$ range as well as identify modifications to the underlying $\mathrm{ZnO}$ due to this over-deposition. The structural model for the a-Si:H coated $\mathrm{ZnO} / \mathrm{Ag}$ BR consisted of a semi-infinite opaque Ag metal layer, a $108 \AA \mathrm{ZnO}+\mathrm{Ag}$ interfacial layer with fixed thickness from the previous analysis given in Table 3, an average $2751 \pm 5 \AA$ bulk $\mathrm{ZnO}$ layer produced by the mean $d_{b}$ values obtained from the simultaneous fitting of the IR and the near IR-UV range spectra, a $84 \pm 1 \AA 0.5 n$-type a-Si:H $+0.5 \mathrm{ZnO}$ Bruggeman effective medium approximation interfacial layer, a $278 \pm 1 \AA$ a-Si:H n-layer, a $30 \pm 1 \AA 0.5$ intrinsic + $0.5 n$-type a-Si:H Bruggeman effective medium approximation interfacial layer, a $3621 \pm 2 \AA$ bulk intrinsic a-Si:H layer, and a $29 \pm 1 \AA$ surface roughness represented using Bruggeman effective medium approximation of 0.5 intrinsic a-Si:H/ 0.5 void volume fractions. The $n$-layer $+\mathrm{ZnO}$ interface, $n$-layer bulk layer, and $n$-layer surface roughness thicknesses are obtained from in situ RTSE measurements and analysis prior to intrinsic a-Si:H deposition. The intrinsic $+n$-type a-Si:H interface thickness is set at the same value as the $n$-layer surface roughness assuming that over-deposited intrinsic a-Si:H fill the voids in the $n$-layer surface. Parameters describing $\varepsilon$ for $\mathrm{ZnO}$ and a-Si:H are listed in Table 5. As with the IR extended analysis of the $\mathrm{ZnO} / \mathrm{Ag}$ sample, a common parameterization of $\varepsilon$ for the materials over the full spectral range was applied, the bulk layer thicknesses for the $\mathrm{ZnO}$ and intrinsic a-Si:H layers were fit independently for spectra collected from each instrument, and all other layer thicknesses were either fixed from prior analyses or kept common between the two sets of spectra. For the $i$-layer, the nominal 
substrate temperature and hydrogen dilution ratio were $T=200^{\circ} \mathrm{C}$ and $R=10$, respectively. The optimized $n$-type a-Si:H thickness was fixed at $278 \AA$ for $R=50$ as found by RTSE growth evolution studies. The depositing material fills the void space in the surface roughness layer of the underlying film. The protrusions in the surface roughness of the substrate film are coated with the depositing material, generating an interface layer associated with the growing film. Bruggeman effective medium approximation defines spectra in $\varepsilon$ for these interfaces.

Table 5. Parameters describing $\varepsilon$ and structure for a $\mathrm{ZnO} / \mathrm{Ag} \mathrm{BR}$ coated with $n$-type and intrinsic a-Si:H. Experimental ellipsometric spectra were collected ex situ using near infrared to ultraviolet $(0.734$ to $5.0 \mathrm{eV}$ ) and infrared $(0.04$ to $0.734 \mathrm{eV})$ spectral range instruments and fit jointly using least squares regression analysis with an unweighted estimator error function, $\sigma=11 \times 10^{-3}$. Parameters describing $\varepsilon$ for $\mathrm{Ag}$ and the $\mathrm{ZnO}+\mathrm{Ag}$ interface were fixed from Tables 2 and 3 respectively. Parameters describing $\varepsilon$ for the $n$-layer were determined from RTSE analysis of data collected at $T=200{ }^{\circ} \mathrm{C}$, parameterized by a Cody-Lorentz oscillator, and then parameter values extrapolated to room temperature. The $\mathrm{ZnO}$ and intrinsic a-Si:H bulk layer thicknesses were allowed to vary separately for each set of spectra; all other parameters are common to both analyses. For $\mathrm{ZnO}$, the parameterization of $\varepsilon$ consisted of two CPPB oscillators with all parameters except the amplitudes fixed to the values in Table 4, four Lorentz oscillators, and $\varepsilon_{\infty}$. For a-Si:H layers, the parameterization of $\varepsilon$ was based on a Cody-Lorentz oscillator and $\varepsilon_{\infty}$. A Sellmeier oscillator and three Gaussian oscillators were added to the parameterization of $\varepsilon$ for intrinsic a-Si:H.

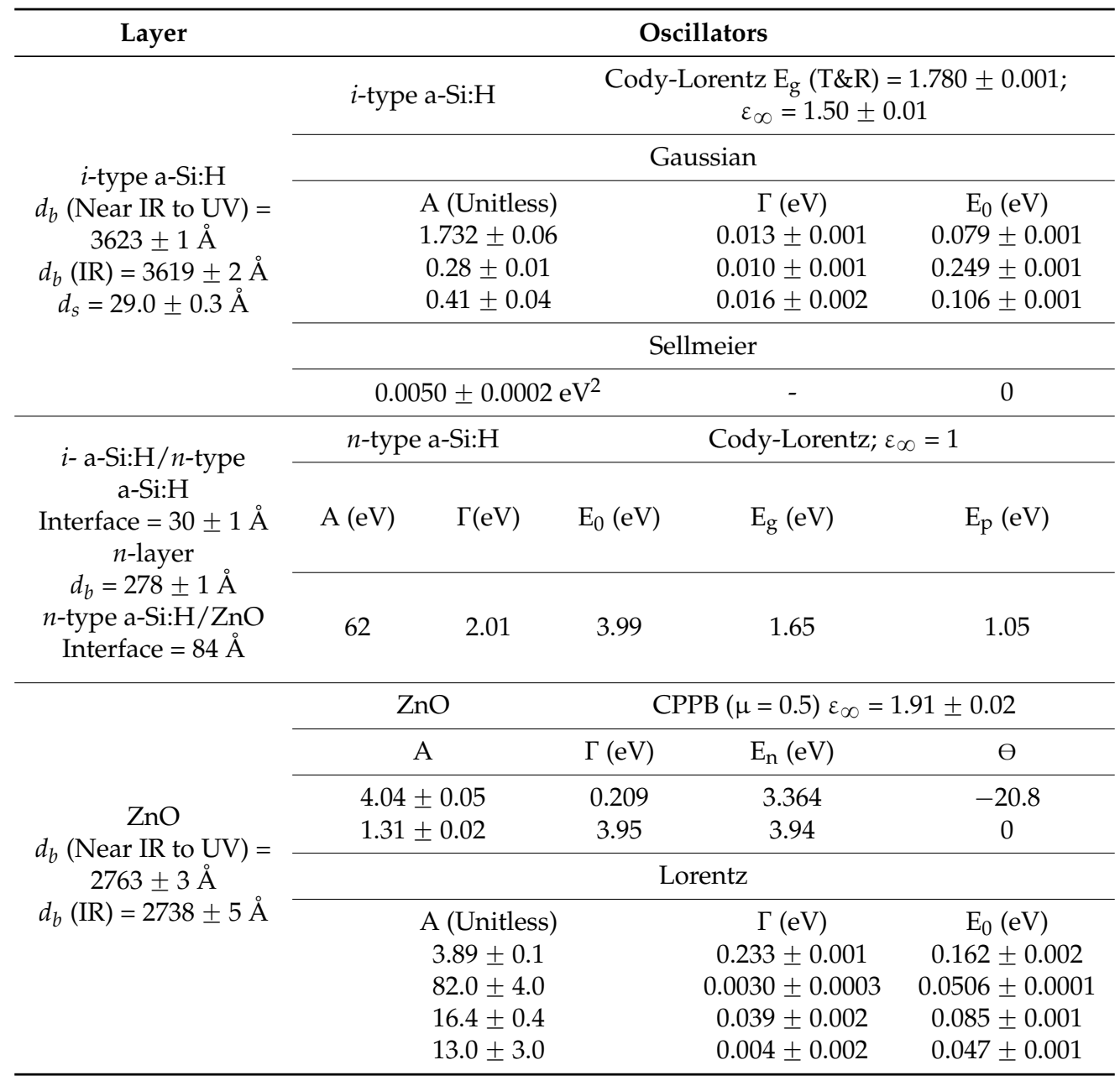

\subsubsection{Phonon Mode Variations in $\mathrm{ZnO}$}

Differences in $\varepsilon$ for the $\mathrm{ZnO}$ are expected when over-coated with a-Si:H. PECVD of a-Si:H raises the temperature of $\mathrm{ZnO}$ to $200^{\circ} \mathrm{C}$ and exposes it to hydrogen in the plasma. There are many studies on the 
growth and various effects of annealing on the optical and structural properties of $\mathrm{ZnO}$ layers [65-70]. It is well known that the properties of $\mathrm{ZnO}$ layers are strongly affected by not only the deposition conditions but also the post-deposition annealing conditions or temperature treatments. Annealing has a large effect on the crystallinity of the layers in terms of grain size, residual strain, and the defect density as compared to as-deposited films. As noted in Table 5, the amplitude of the CPPB oscillators of $\mathrm{ZnO}$ over-coated with a-Si:H are fit to account for changes in $\varepsilon$ occurring during PECVD of the a-Si:H layers. The increase in amplitude for higher energy absorption features in $\varepsilon$ and the decrease in film thickness compared to the sample without a-Si:H coating at $T=200{ }^{\circ} \mathrm{C}$ indicate that the as-deposited $\mathrm{ZnO}$ film densifies and increases the degree of crystallinity after annealing at the a-Si:H deposition temperature. These variations are generally consistent with literature $[69,70]$, in that the imaginary component of the optical response related to electronic transitions increases in amplitude and sharpens. However, Liu et al. reports a decrease in the real part of the complex index of refraction in the transparent region, which they attribute to void forming along with larger crystalline grains. In our samples, void formation is not observed optically, however the decrease in thickness implies that crystallite growth has occurred which coupled with the higher observed real part of $\varepsilon$ indicates that this film is now overall more densely packed. The comparison of different phonon modes in $\mathrm{ZnO}$ with and without a-Si:H coating is shown in Figure 9. The characteristic TO modes with $\mathrm{A}_{1}$ and $\mathrm{E}_{1}$ symmetry at $0.0467 \mathrm{eV}\left(376.66 \mathrm{~cm}^{-1}\right)$ and $0.0506 \mathrm{eV}\left(408.12 \mathrm{~cm}^{-1}\right)$ are present and able to be resolved [51-53]. The vibrational mode at $0.0847 \mathrm{eV}\left(683.15 \mathrm{~cm}^{-1}\right)$ can be attributed to longitudinal optical (LO) mode with $\mathrm{E}_{1}$ symmetry [52]. The orientation of grains in the film could be a reason for shifting of modes to slightly higher or lower wavenumbers. The splitting of the peak observed at $404 \mathrm{~cm}^{-1}$ for the uncoated $\mathrm{ZnO}$ into two expected peaks at 377 and $408 \mathrm{~cm}^{-1}$ for $\mathrm{ZnO}$ over-coated with a-Si:H and appearance of the $683 \mathrm{~cm}^{-1}$ mode is likely due to grain size increases or a reduction in defect density from annealing at the a-Si:H deposition temperature of $200^{\circ} \mathrm{C}$ [68]. The increase in amplitude for $\varepsilon_{2}$ of phonon mode at $408 \mathrm{~cm}^{-1}$ also supports the idea that grain restructuring and material densification occurs. The presence of an additional absorption mode at $1306.62 \mathrm{~cm}^{-1}$ $(0.162 \mathrm{eV})$ can be associated with oxygen-hydrogen $(\mathrm{O}-\mathrm{H})$ bonds in the thin film, such as the formation of zinc hydroxide or absorbed water or stretching modes of hydrogen bonded to heavier elements like zinc [54]. The large broadening of this absorption peak could be due to the modification or damage to the $\mathrm{ZnO}$ as a result of exposure to hydrogen in the plasma.

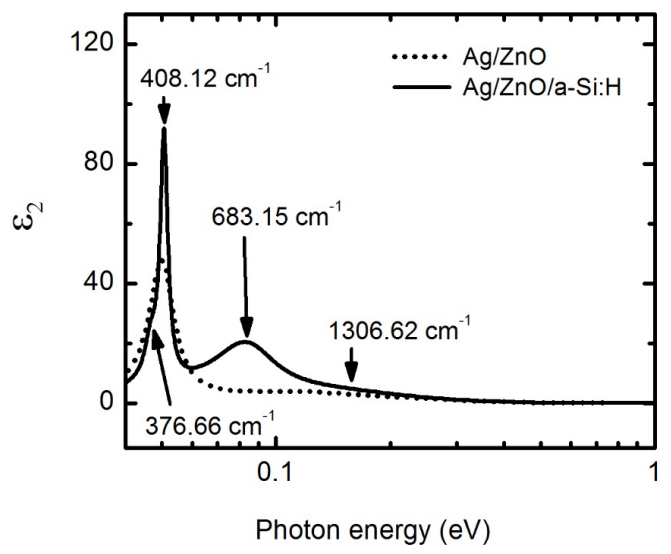

Figure 9. Comparison of lower energy features in $\varepsilon_{2}$ as a function of photon energy for $\mathrm{ZnO}$ with (solid line) and without (dotted line) over-deposition of a-Si:H. Parameters describing the sample without and with over-deposition of are listed in Tables 4 and 5 respectively.

\subsubsection{Chemical Bonding in a-Si:H}

After $\mathrm{ZnO}$ deposition, a 278 A thick $n$-layer was deposited onto a $\mathrm{ZnO} / \mathrm{Ag}$ coated substrate with deposition conditions given in Table 1 . The $n$-layer optical properties, as well as its $d_{b}$ and $d_{s}$, were 
obtained from RTSE analysis. The final numerically inverted spectra in $\varepsilon$ for the $n$-layer were fit to a Cody-Lorentz oscillator [71]. The Cody-Lorentz oscillator is described by:

$$
\varepsilon_{2}(E)=\left\{\begin{array}{ll}
\frac{A E_{0} \Gamma E}{\left(E^{2}-E_{0}^{2}\right)^{2}+\Gamma^{2} E^{2}} \frac{\left(E-E_{g}\right)^{2}}{\left(E-E_{g}\right)^{2}+E_{p}^{2}} & E>E_{g} \\
0 & E \leqslant E_{g}
\end{array},\right.
$$

and

$$
\varepsilon_{1}(E)=\frac{2}{\pi} P \int_{0}^{\infty} \frac{\xi \varepsilon_{2}(\xi)}{\xi^{2}-E^{2}} d \xi
$$

where $A$ is the amplitude, $\Gamma$ is the broadening, $E_{0}$ is the resonance energy, $E_{g}$ represents an absorption onset determined from a parabolic band constant dipole matrix element, and $E_{p}+E_{g}$ represents the transition between Cody gap-like and Lorentz-like behavior. Analytical Kramers-Kronig transformation of $\varepsilon_{2}$ yields $\varepsilon_{1}$. Parameters describing $\varepsilon$ for the $n$-layer at the deposition temperature $T=200{ }^{\circ} \mathrm{C}$ are $A=59 \pm 2 \mathrm{eV}, \Gamma=2.12 \pm 0.02 \mathrm{eV}, E_{0}=3.99 \pm 0.01 \mathrm{eV}, E_{g}=1.58 \pm 0.04 \mathrm{eV}$, and $E_{p}=0.96 \pm 0.09 \mathrm{eV}$.

Figure 10 shows spectra in $\varepsilon$ for the $R=10$ a-Si:H intrinsic layer parameterized using a Cody-Lorentz oscillator at high energies and Gaussian oscillators to represent the IR vibrational modes. Each Gaussian oscillator [72] is described by:

$$
\begin{gathered}
\varepsilon_{2}(E)=A e^{-\left(\frac{E-E_{n}}{\sigma}\right)^{2}}-A e^{-\left(\frac{E+E_{n}}{\sigma}\right)^{2}} \\
\sigma=\frac{\Gamma}{2 \sqrt{\ln (2)}}
\end{gathered}
$$

where $A, \Gamma$, and $E_{n}$ represent amplitude, broadening, and resonance energy respectively, and $\varepsilon_{1}$ is generated by Kramers-Kronig transformation of $\varepsilon_{2}$ (Equation 8). Fit parameters are listed in Table 5. The Cody-Lorentz oscillator parameters for intrinsic a-Si:H were linked to a single fit parameter, $E_{g}$ from transmission and reflection spectroscopy, by linear relationships previously determined for PV device quality a-Si:H [71]. This technique minimizes the number of fit parameters allowing for extraction of physically realistic $\varepsilon$. Parameters describing spectra in $\varepsilon$ for the underlying $n$-layer were extrapolated based on previously observed trends in the Cody-Lorentz oscillator parameters with temperature [73].

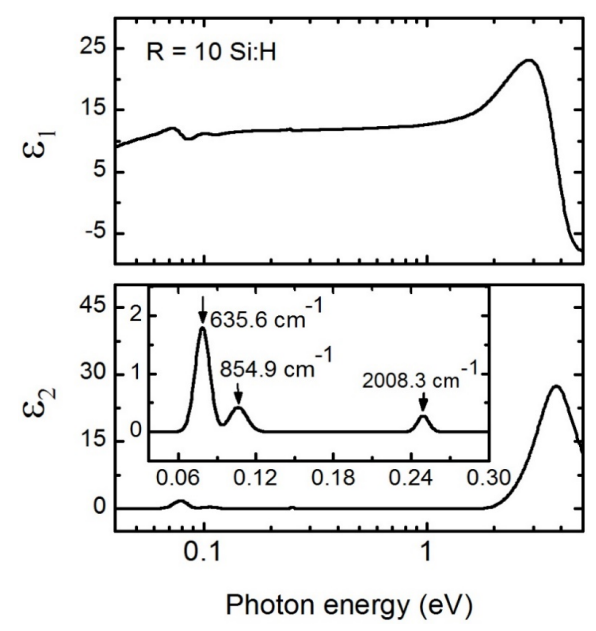

Figure 10. Spectra in $\varepsilon$ (top panel, real part $\varepsilon_{1}$; bottom panel, imaginary part $\varepsilon_{2}$ ) extracted over a spectral range from 0.04 to $5 \mathrm{eV}$ for $3621 \pm 2 \AA \mathrm{R}=10$ a-Si:H films on BR over-coated with a $R=50 n$-layer. The inset shows lower energy features in $\varepsilon_{2}$ as a function of photon energy representing $\mathrm{Si}-\mathrm{H}_{\mathrm{n}}$ vibrational modes as modeled by Gaussian oscillators. 
IR vibrational studies of a-Si:H have been useful in understanding the role of $\mathrm{Si}-\mathrm{H}$ bonding in determining a-Si:H properties. High mobility and reactivity of hydrogen enables passivation of the electronic defect states in a-Si:H and relaxes the a-Si:H network to improve electronic and structural properties. IR-absorption studies have shown that hydrogen in a-Si:H is bonded as $\mathrm{Si}-\mathrm{H}_{n}$, with $n=1,2$, and $3[35,74]$. IR features in $\varepsilon$ for the intrinsic a-Si:H film are highlighted in the inset of Figure 10. Spectra in $\varepsilon$ for a-Si:H in the $n$-i-p device configuration exhibited bending modes near $0.079 \mathrm{eV}\left(635.6 \mathrm{~cm}^{-1}\right)$ and a stretching monohydride $(\mathrm{Si}-\mathrm{H})$ mode around $0.249 \mathrm{eV}\left(2008.3 \mathrm{~cm}^{-1}\right)$. In addition to the expected $\mathrm{Si}-\mathrm{H}$ modes, this a-Si:H sample exhibited an absorption mode centered around $0.106 \mathrm{eV}\left(854.9 \mathrm{~cm}^{-1}\right)$, which can be attributed to the bending or scissoring $\mathrm{Si}-\mathrm{H}_{2}$ dihydride mode. The peak centered $2100 \mathrm{~cm}^{-1}$ assigned to the dihydride $\left(\mathrm{Si}-\mathrm{H}_{2}\right)$ or clustered hydrogen is not observed. Although $\mathrm{Si}-\mathrm{H}$ and $\mathrm{Si}-\mathrm{H}_{2}$ bonding modes were previously resolved in ellipsometric measurements for other samples [75], we can resolve only the Si-H peak here possibly due to a much lower amplitude of the $\mathrm{Si}-\mathrm{H}_{2}$ peak or reduced sensitivity to that feature in this particular sample. In addition to mode deconvolution in $\varepsilon$, the Si- $\mathrm{H}_{2}$ mode is also not observed in the extinction coefficient, $k$, or the absorption coefficient, $\alpha$, obtained from $\varepsilon$. The absence of that peak usually confirms the presence of ordered dense Si:H material [76,77]. The amplitude of $\varepsilon_{1}$ and the relatively high amplitude of the near IR to UV absorption feature in $\varepsilon_{2}$ indicate that this is dense material and suitable for PV devices.

\section{Summary and Conclusions}

RTSE and IR-SE have been demonstrated as a useful metrology technique for characterization of PECVD Si:H layers and components of the BR structure used in n-i-p a-Si:H solar cells. Growth evolution diagrams were developed for $n$-type, intrinsic, and $p$-type Si:H to identify the regions of optimized protocrystalline a-Si:H material for the respective thicknesses used in the solar cell configuration. IR to UV ex situ SE measurements and analysis were used to determine spectra in $\varepsilon$ for $\mathrm{Ag}, \mathrm{ZnO}$, the $\mathrm{ZnO}+\mathrm{Ag}$ interface, and protocrystalline intrinsic a-Si:H in the device configuration. Free carrier absorption in $\mathrm{Ag}$ and the $\mathrm{ZnO}+\mathrm{Ag}$ interface, the particle plasmon feature in the $\mathrm{ZnO} / \mathrm{Ag}$ interface, and four IR phonon modes in $\mathrm{ZnO}$ were identified. $\mathrm{Si}-\mathrm{H}_{n}$ bonding modes were identified in $\varepsilon$ obtained from intrinsic a-Si:H prepared on a $n$-type a-Si:H coated BR. IR-SE has been demonstrated to be sensitive to bonding characteristics of a-Si:H layers in the PV device configuration. Overall, the results and analysis procedures developed here are applicable to more directly relating film properties, as obtained by non-destructive measurements in the PV device configuration, with variations in device performance.

Acknowledgments: We gratefully acknowledge support from the University of Toledo start up funds and the Ohio Department of Development (ODOD) Ohio Research Scholar Program entitled Northwest Ohio Innovators in Thin Film Photovoltaics, Grant No. TECH 09-025.

Author Contributions: Laxmi Karki Gautam primarily fabricated samples, collected and analyzed RTSE data, and analyzed ex situ SE data. Maxwell M. Junda fabricated samples and performed RTSE data collection and analysis. Hamna F. Haneef performed IR-SE measurements and data analysis. Robert W. Collins and Nikolas J. Podraza guided the experiment design and data analysis. Laxmi Karki Gautam and Nikolas J. Podraza wrote the paper with input from Maxwell M. Junda, Hamna F. Haneef, and Robert W. Collins.

Conflicts of Interest: The authors have no conflict of interest. The funding sponsors had no role in the design of the study, in the collection, analyses, or interpretation of data; in the writing of the manuscript; and in the decision to publish the results.

\section{References}

1. Robertson, J. Deposition mechanism of hydrogenated amorphous silicon. J. Appl. Phys. 2000, 87, $2608-2617$. [CrossRef]

2. Collins, R.; Ferlauto, A.; Ferreira, G.; Chen, C.; Koh, J.; Koval, R.; Lee, Y.; Pearce, J.; Wronski, C. Evolution of microstructure and phase in amorphous, protocrystalline, and microcrystalline silicon studied by real time spectroscopic ellipsometry. Sol. Energy Mater. Sol. Cells 2003, 78, 143-180. [CrossRef] 
3. Robertson, J. Growth mechanism of hydrogenated amorphous silicon. J. Non-Cryst. Solids 2000, 266, 79-83. [CrossRef]

4. Fujiwara, H.; Kondo, M.; Matsuda, A. Real-time spectroscopic ellipsometry studies of the nucleation and grain growth processes in microcrystalline silicon thin films. Phys. Rev. B 2001, 63. [CrossRef]

5. Schiff, E.A.; Deng, X. Amorphous silicon-based solar cells. In Handbook of Photovoltaic Science and Engineering; Luque, S.H.A., Ed.; Wiley: New York, NY, USA, 2003; pp. 487-545.

6. Guha, S.; Cohen, D.; Schiff, E.; Stradins, P.; Taylor, P.; Yang, J. Industry-academia partnership helps drive commercialization of new thin-film silicon technology. Photovolt. Int. 2011, 134. Available online: http:/ / citeseerx.ist.psu.edu/viewdoc/download?doi=10.1.1.397.3368\&rep=rep1\&type=pdf (accessed on 1 September 2011).

7. Koh, J.; Ferlauto, A.; Rovira, P.; Wronski, C.; Collins, R. Evolutionary phase diagrams for plasma-enhanced chemical vapor deposition of silicon thin films from hydrogen-diluted silane. Appl. Phys. Lett. 1999, 75, 2286-2288. [CrossRef]

8. Matsui, T.; Sai, H.; Saito, K.; Kondo, M. High-efficiency thin-film silicon solar cells with improved light-soaking stability. Prog. Photovolt. Res. Appl. 2013, 21, 1363-1369. [CrossRef]

9. Sai, H.; Matsui, T.; Matsubara, K.; Kondo, M.; Yoshida, I. 11.0\%-Efficient thin-film microcrystalline silicon solar cells with honeycomb textured substrates. IEEE J. Photovolt. 2014, 4, 1349-1353. [CrossRef]

10. Yan, B.; Yue, G.; Sivec, L.; Yang, J.; Guha, S.; Jiang, C.-S. Innovative dual function nc-SiO ${ }_{x}: H$ layer leading to a $>16 \%$ efficient multi-junction thin-film silicon solar cell. Appl. Phys. Lett. 2011, 99. [CrossRef]

11. Rovira, P.; Ferlauto, A.; Koval, R.; Wronski, C.; Collins, R.; Ganguly, G. Real time optics of p-type silicon deposition on specular and textured $\mathrm{ZnO}$ surfaces. In Proceedings of the Conference Record of the Twenty-Eighth IEEE Photovoltaic Specialists Conference, Anchorage, AK, USA, 15-22 September 2000; pp. 772-775.

12. Koval, R.; Chen, C.; Ferreira, G.; Ferlauto, A.; Pearce, J.; Rovira, P.; Wronski, C.; Collins, R. Maximization of the open circuit voltage for hydrogenated amorphous silicon nip solar cells by incorporation of protocrystalline silicon p-type layers. Appl. Phys. Lett. 2002, 81, 1258-1260. [CrossRef]

13. Ferreira, G.; Ferlauto, A.; Pearce, J.; Wronski, C.; Ross, C.; Collins, R. Comparison of phase diagrams for vhf and rf plasma-enhanced chemical vapor deposition of Si: H films. In MRS Proceedings; Cambridge University Press: Cambridge, UK, 2004; pp. A5.2.1-A5.2.6.

14. Stoke, J.; Dahal, L.; Li, J.; Podraza, N.; Cao, X.; Deng, X.; Collins, R. Optimization of Si:H multijunction nip solar cells through the development of deposition phase diagrams. In Proceedings of the 33rd IEEE Photovoltaic Specialists Conference, PVSC '08, San Diego, CA, USA, 11-16 May 2008; pp. 1-6.

15. Dahal, L.R.; Huang, Z.; Attygalle, D.; Sestak, M.N.; Salupo, C.; Marsillac, Y.; Collins, R. Application of real time spectroscopic ellipsometry for analysis of roll-to-roll fabrication of Si:H solar cells on polymer substrates. In Proceedings of the 2010 35th IEEE Photovoltaic Specialists Conference (PVSC), Honolulu, HI, USA, 20-25 June 2010; pp. 000631-000636.

16. Huang, Z.; Dahal, L.; Salupo, C.; Ferlauto, A.; Podraza, N.J.; Collins, R.W. Optimization of a-Si:H pin solar cells through development of n-layer growth evolution diagram and large area mapping. In Proceedings of the 2013 IEEE 39th Photovoltaic Specialists Conference (PVSC), Tampa, FL, USA, 16-21 June 2013; pp. 1788-1793.

17. Murata, D.; Yuguchi, T.; Fujiwara, H. Characterization of $\mu \mathrm{c}-\mathrm{Si}: \mathrm{H} / \mathrm{a}-\mathrm{Si}: \mathrm{H}$ tandem solar cell structures by spectroscopic ellipsometry. Thin Solid Films 2014, 571, 756-761. [CrossRef]

18. Junda, M.M.; Shan, A.; Koirala, P.; Collins, R.W.; Podraza, N.J. Spectroscopic ellipsometry applied in the full pin a-Si:H solar cell device configuration. IEEE J. Photovolt. 2015, 5, 307-312. [CrossRef]

19. Yue, G.; Yan, B.; Ganguly, G.; Yang, J.; Guha, S.; Teplin, C.W. Material structure and metastability of hydrogenated nanocrystalline silicon solar cells. Appl. Phys. Lett. 2006, 88. [CrossRef]

20. Yue, G.; Sivec, L.; Owens, J.M.; Yan, B.; Yang, J.; Guha, S. Optimization of back reflector for high efficiency hydrogenated nanocrystalline silicon solar cells. Appl. Phys. Lett. 2009, 95. [CrossRef]

21. Vetterl, O.; Finger, F.; Carius, R.; Hapke, P.; Houben, L.; Kluth, O.; Lambertz, A.; Mück, A.; Rech, B.; Wagner, H. Intrinsic microcrystalline silicon: A new material for photovoltaics. Sol. Energy Mater. Sol. Cells 2000, 62, 97-108. [CrossRef]

22. Shah, A.; Meier, J.; Vallat-Sauvain, E.; Wyrsch, N.; Kroll, U.; Droz, C.; Graf, U. Material and solar cell research in microcrystalline silicon. Sol. Energy Mater. Sol. Cells 2003, 78, 469-491. [CrossRef] 
23. Dahal, L.R.; Li, J.; Stoke, J.A.; Huang, Z.; Shan, A.; Ferlauto, A.S.; Wronski, C.R.; Collins, R.W.; Podraza, N.J. Applications of real-time and mapping spectroscopic ellipsometry for process development and optimization in hydrogenated silicon thin-film photovoltaics technology. Sol. Energy Mater. Sol. Cells 2014, 129, 32-56. [CrossRef]

24. Shan, A.; Fried, M.; Juhasz, G.; Major, C.; Polgár, O.; Németh, Á.; Petrik, P.; Dahal, L.R.; Chen, J.; Huang, Z. High-speed imaging/mapping spectroscopic ellipsometry for in-line analysis of roll-to-roll thin-film photovoltaics. IEEE J. Photovolt. 2014, 4, 355-361. [CrossRef]

25. Aryal, P.; Pradhan, P.; Attygalle, D.; Ibdah, A.-R.; Aryal, K.; Ranjan, V.; Marsillac, S.; Podraza, N.J.; Collins, R.W. Real-time, in-line, and mapping spectroscopic ellipsometry for applications in Cu (in Ga) Se metrology. IEEE J. Photovolt. 2014, 4, 333-339. [CrossRef]

26. Koirala, P.; Tan, X.; Li, J.; Podraza, N.J.; Marsillac, S.; Rockett, A.; Collins, R.W. Mapping spectroscopic ellipsometry of CdTe solar cells for property-performance correlations. In Proceedings of the 2014 IEEE 40th Photovoltaic Specialist Conference (PVSC), Denver, CO, USA, 8-13 June 2014; pp. 0674-0679.

27. Dahal, L.R.; Sainju, D.; Li, J.; Stoke, J.A.; Podraza, N.; Deng, X.; Collins, R.W. Plasmonic characteristics of $\mathrm{Ag} / \mathrm{ZnO}$ back-reflectors for thin film Si photovoltaics. In Proceedings of the 33rd IEEE Photovoltaic Specialists Conference, PVSC '08, San Diego, CA, USA, 11-16 May 2008; pp. 1-6.

28. Dahal, L.R.; Sainju, D.; Podraza, N.; Marsillac, S.; Collins, R. Real time spectroscopic ellipsometry of $\mathrm{Ag} / \mathrm{ZnO}$ and $\mathrm{Al} / \mathrm{ZnO}$ interfaces for back-reflectors in thin film Si:H photovoltaics. Thin Solid Films 2011, 519, 2682-2687. [CrossRef]

29. Oldham, W. Numerical techniques for the analysis of lossy films. Surf. Sci. 1969, 16, 97-103. [CrossRef]

30. Aspnes, D. Minimal-data approaches for determining outer-layer dielectric responses of films from kinetic reflectometric and ellipsometric measurements. Appl. Phys. Lett. 1993, 62, 343-345. [CrossRef]

31. Ferlauto, A.; Ferreira, G.; Koval, R.; Pearce, J.; Wronski, C.; Collins, R.; Al-Jassim, M.; Jones, K. Evaluation of compositional depth profiles in mixed-phase (amorphous + crystalline) silicon films from real time spectroscopic ellipsometry. Thin Solid Films 2004, 455, 665-669. [CrossRef]

32. Karki Gautam, L.; Haneef, H.; Junda, M.; Saint John, D.; Podraza, N. Approach for extracting complex dielectric function spectra in weakly-absorbing regions. Thin Solid Films 2014, 571, 548-553. [CrossRef]

33. Podraza, N.J.; Saint John, D.B.; Ko, S.W.; Schulze, H.M.; Li, J.; Dickey, E.C.; Trolier-McKinstry, S. Optical and structural properties of solution deposited nickel manganite thin films. Thin Solid Films 2011, 519, 2919-2923. [CrossRef]

34. Knights, J.C.; Lucovsky, G.; Nemanich, R.J. Defects in plasma-deposited a-Si:H. J. Non-Cryst. Solids 1979, 32, 393-403. [CrossRef]

35. Langford, A.A.; Fleet, M.L.; Nelson, B.P.; Lanford, W.A.; Maley, N. Infrared absorption strength and hydrogen content of hydrogenated amorphous silicon. Phys. Rev. B 1992, 45, 13367-13377. [CrossRef]

36. Podraza, N.J.; Saint John, D.B. Optical characterization of structurally graded $\mathrm{Si}_{1-x} \mathrm{Ge}_{x}: \mathrm{H}$ thin films. In Proceedings of the 2012 38th IEEE Photovoltaic Specialists Conference (PVSC), Austin, TX, USA, 3-8 June 2012; pp. 000354-000359.

37. Dahal, L.R.; Zhiquan, H.; Attygalle, D.; Salupo, C.; Marsillac, S.; Podraza, N.J.; Collins, R.W. Correlations between mapping spectroscopic ellipsometry results and solar cell performance for evaluations of nonuniformity in thin-film silicon photovoltaics. IEEE J. Photovolt. 2013, 3, 387-393. [CrossRef]

38. Lee, J.; Rovira, P.; An, I.; Collins, R. Rotating-compensator multichannel ellipsometry: Applications for real time Stokes vector spectroscopy of thin film growth. Rev. Sci. Instrum. 1998, 69, 1800-1810. [CrossRef]

39. Johs, B.D.; Woollam, J.A.; Herzinger, C.M.; Hilfiker, J.N.; Synowicki, R.A.; Bungay, C.L. Overview of variable-angle spectroscopic ellipsometry (VASE): II. In Advanced Applications, Society of Photo-Optical Instrumentation Engineers (SPIE) Conference Series; Society of Photo-Optical Instrumentation Engineers: Bellingham, WA, USA, 1999; pp. 29-58.

40. Johs, B.; Herzinger, C.M. Quantifying the accuracy of ellipsometer systems. Phys. Status Solidi 2008, 5, 1031-1035. [CrossRef]

41. Hilfiker, J.N.; Bungay, C.L.; Synowicki, R.A.; Tiwald, T.E.; Herzinger, C.M.; Johs, B.; Pribil, G.K.; Woollam, J.A. Progress in spectroscopic ellipsometry: Applications from vacuum ultraviolet to infrared. J. Vac. Sci. Technol. A 2003, 21, 1103-1108. [CrossRef]

42. Aspnes, D.E. Optical properties of thin films. Thin Solid Films 1982, 89, 249-262. [CrossRef] 
43. Fujiwara, H.; Koh, J.; Rovira, P.; Collins, R. Assessment of effective-medium theories in the analysis of nucleation and microscopic surface roughness evolution for semiconductor thin films. Phys. Rev. B 2000, 61. [CrossRef]

44. Azzam, R.; Bashara, N. Ellipsometry and Polarized Light; North-Holland: Amsterdam, The Netherlands, 1981.

45. Tiwald, T.E.; Thompson, D.W.; Woollam, J.A.; Paulson, W.; Hance, R. Application of IR variable angle spectroscopic ellipsometry to the determination of free carrier concentration depth profiles. Thin Solid Films 1998, 313-314, 661-666. [CrossRef]

46. Aspnes, D.E. Handbook on Semiconductors; Balkanski, A.M., Ed.; North-Holland: Amsterdam, The Netherlands, 1980; pp. 125-127.

47. Collins, R.W.; Ferlauto, A.S. Handbook of Ellipsometry; Tompkins, H., Irene, E.A., Eds.; William Andrew: Norwich, NY, USA, 2005; pp. 159-171.

48. Sainju, D.; van den Oever, P.J.; Podraza, N.J.; Syed, M.; Stoke, J.A.; Jie, C.; Xiesen, Y.; Xunming, D.; Collins, R.W. Origin of optical losses in $\mathrm{Ag} / \mathrm{ZnO}$ back-reflectors for thin film Si photovoltaics. In Proceedings of the Conference Record of the 2006 IEEE 4th World Conference on Photovoltaic Energy Conversion, Waikoloa, HI, USA, 7-12 May 2006; pp. 1732-1735.

49. Ferlauto, A.S.; Collins, R.W. Handbook of Ellipsometry; Tompkins, H., Irene, E.A., Eds.; William Andrew: Norwich, NY, USA, 2005; pp. 125-129.

50. Jellison, G.E.; Boatner, L.A. Optical functions of uniaxial $\mathrm{ZnO}$ determined by generalized ellipsometry. Phys. Rev. B 1998, 58, 3586-3589. [CrossRef]

51. Bundesmann, C.; Ashkenov, N.; Schubert, M.; Rahm, A.; Wenckstern, H.; Kaidashev, E.; Lorenz, M.; Grundmann, M. Infrared dielectric functions and crystal orientation of a-plane $\mathrm{ZnO}$ thin films on r-plane sapphire determined by generalized ellipsometry. Thin Solid Films 2004, 455, 161-166. [CrossRef]

52. Ashkenov, N.; Mbenkum, B.N.; Bundesmann, C.; Riede, V.; Lorenz, M.; Spemann, D.; Kaidashev, E.M.; Kasic, A.; Schubert, M.; Grundmann, M.; et al. Infrared dielectric functions and phonon modes of high-quality ZnO films. J. Appl. Phys. 2003, 93, 126-133. [CrossRef]

53. Tzolov, M.; Tzenov, N.; Dimova-Malinovska, D.; Kalitzova, M.; Pizzuto, C.; Vitali, G.; Zollo, G.; Ivanov, I. Vibrational properties and structure of undoped and Al-doped $\mathrm{ZnO}$ films deposited by RF magnetron sputtering. Thin Solid Films 2000, 379, 28-36. [CrossRef]

54. Keyes, B.; Gedvilas, L.; Li, X.; Coutts, T. Infrared spectroscopy of polycrystalline ZnO and ZnO:N thin films. J. Cryst. Growth 2005, 281, 297-302. [CrossRef]

55. Saint John, D.S.; Shin, H.-B.; Lee, M.-Y.; Ajmera, S.; Syllaios, A.; Dickey, E.; Jackson, T.; Podraza, N. Influence of microstructure and composition on hydrogenated silicon thin film properties for uncooled microbolometer applications. J. Appl. Phys. 2011, 110, 033714. [CrossRef]

56. Podraza, N.; Li, J.; Wronski, C.; Dickey, E.; Collins, R. Analysis of controlled mixed-phase (amorphous + microcrystalline) silicon thin films by real time spectroscopic ellipsometry. J. Vac. Sci. Technol. A 2009, 27, 1255-1259. [CrossRef]

57. Podraza, N.; Li, J.; Wronski, C.; Dickey, E.; Horn, M.; Collins, R. Analysis of $\mathrm{Si}_{1--x} \mathrm{Ge}_{x}: \mathrm{H}$ thin films with graded composition and structure by real time spectroscopic ellipsometry. Phys. Status Solidi 2008, 205, 892-895. [CrossRef]

58. Aspnes, D.; Theeten, J. Spectroscopic analysis of the interface between Si and its thermally grown oxide. J. Electrochem. Soc. 1980, 127, 1359-1365. [CrossRef]

59. Kroll, U.; Meier, J.; Shah, A.; Mikhailov, S.; Weber, J. Hydrogen in amorphous and microcrystalline silicon films prepared by hydrogen dilution. J. Appl. Phys. 1996, 80, 4971-4975. [CrossRef]

60. Funde, A.M.; Bakr, N.A.; Kamble, D.K.; Hawaldar, R.R.; Amalnerkar, D.P.; Jadkar, S.R. Influence of hydrogen dilution on structural, electrical and optical properties of hydrogenated nanocrystalline silicon (nc-Si:H) thin films prepared by plasma enhanced chemical vapour deposition (PE-CVD). Sol. Energy Mater. Sol. Cells 2008, 92, 1217-1223. [CrossRef]

61. Cao, X.; Stoke, J.A.; Li, J.; Podraza, N.J.; Du, W.; Yang, X.; Attygalle, D.; Liao, X.; Collins, R.W.; Deng, X. Fabrication and optimization of single-junction nc-Si:H n-i-p solar cells using Si:H phase diagram concepts developed by real time spectroscopic ellipsometry. J. Non-Cryst. Solids 2008, 354, 2397-2402. [CrossRef]

62. Yan, B.; Yue, G.; Yang, J.; Guha, S.; Williamson, D.; Han, D.; Jiang, C.-S. Hydrogen dilution profiling for hydrogenated microcrystalline silicon solar cells. Appl. Phys. Lett. 2004, 85, 1955-1957. [CrossRef] 
63. Wronski, C.; Collins, R. Phase engineering of a-Si:H solar cells for optimized performance. Sol. Energy 2004, 77, 877-885. [CrossRef]

64. Pearce, J.M.; Podraza, N.; Collins, R.W.; Al-Jassim, M.M.; Jones, K.M.; Deng, J.; Wronski, C.R. Optimization of open circuit voltage in amorphous silicon solar cells with mixed-phase (amorphous + nanocrystalline) p-type contacts of low nanocrystalline content. J. Appl. Phys. 2007, 101. [CrossRef]

65. Jung, M.; Lee, J.; Park, S.; Kim, H.; Chang, J. Investigation of the annealing effects on the structural and optical properties of sputtered ZnO thin films. J. Cryst. Growth 2005, 283, 384-389. [CrossRef]

66. Kang, H.S.; Kang, J.S.; Kim, J.W.; Lee, S.Y. Annealing effect on the property of ultraviolet and green emissions of ZnO thin films. J. Appl. Phys. 2004, 95, 1246-1250. [CrossRef]

67. Puchert, M.; Timbrell, P.; Lamb, R. Post deposition annealing of radio frequency magnetron sputtered $\mathrm{ZnO}$ films. J.Vac. Sci. Technol. A 1996, 14, 2220-2230. [CrossRef]

68. Rolo, A.G.; de Campos, J.A.; Viseu, T.; de Lacerda-Arôso, T.; Cerqueira, M. The annealing effect on structural and optical properties of $\mathrm{ZnO}$ thin films produced by rf sputtering. Superlattices Microstruct. 2007, 42, 265-269. [CrossRef]

69. Al Asmar, R.; Ferblantier, G.; Mailly, F.; Gall-Borrut, P.; Foucaran, A. Effect of annealing on the electrical and optical properties of electron beam evaporated ZnO thin films. Thin Solid Films 2005, 473, 49-53. [CrossRef]

70. Liu, Y.C.; Tung, S.K.; Hsieh, J.H. Influence of annealing on optical properties and surface structure of ZnO thin films. J. Crystal Growth 2006, 287, 105-111. [CrossRef]

71. Ferlauto, A.; Ferreira, G.; Pearce, J.; Wronski, C.; Collins, R.; Deng, X.; Ganguly, G. Analytical model for the optical functions of amorphous semiconductors from the near-infrared to ultraviolet: Applications in thin film photovoltaics. J. Appl. Phys. 2002, 92, 2424-2436. [CrossRef]

72. De Meneses, D.; Malki, M.; Echegut, P. Structure and lattice dynamics of binary lead silicate glasses investigated by infrared spectroscopy. J. Non-Cryst. Solids 2006, 352, 769-776. [CrossRef]

73. Podraza, N.; Wronski, C.; Horn, M.; Collins, R. Dielectric functions of a-Si $i_{1-x} \mathrm{Ge}_{x}: \mathrm{H}$ vs. Ge content, temperature, and processing: Advances in optical function parameterization. Mater. Res. Soc. Symp. Proc. 2006, A10. [CrossRef]

74. Brodsky, M.; Cardona, M.; Cuomo, J. Infrared and Raman spectra of the silicon-hydrogen bonds in amorphous silicon prepared by glow discharge and sputtering. Phys. Rev. B 1977, 16. [CrossRef]

75. Saint John, D.B.; Shen, H.; Shin, H.-B.; Jackson, T.N.; Podraza, N.J. Infrared dielectric functions of hydrogenated amorphous silicon thin films determined by spectroscopic ellipsometry. In Proceedings of the 2012 38th IEEE Photovoltaic Specialists Conference (PVSC), Austin, TX, USA, 3-8 June 2012; pp. 003112-003117.

76. Müllerová, J.; Jurečka, S.; Šutta, P. Optical characterization of polysilicon thin films for solar applications. Sol. Energy 2006, 80, 667-674. [CrossRef]

77. Smets, A.; Kessels, W.; van de Sanden, M. Vacancies and voids in hydrogenated amorphous silicon. Appl. Phys. Lett. 2003, 82, 1547-1549. [CrossRef]

(C) 2016 by the authors; licensee MDPI, Basel, Switzerland. This article is an open access article distributed under the terms and conditions of the Creative Commons by Attribution (CC-BY) license (http://creativecommons.org/licenses/by/4.0/). 